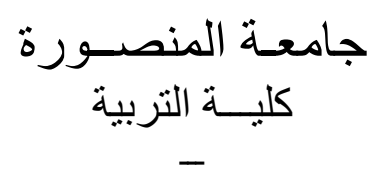

\title{
القيادة الأصيلة لدى قادة مدارس التعليم العام بمحافظة ينبع وعلاقتها بالعدالة الإجرائية المدركة هن وجهة نظر المعلمين
}

\author{
إعداد

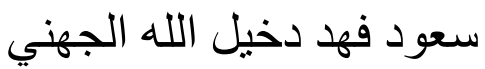

$$
\begin{aligned}
& \text { إنشر اف بعن } \\
& \text { أ.د / صالح بن علي يعن الله القرني } \\
& \text { أستاذ الإدارة التربوية المشارك العك } \\
& \text { جامعة الملك عبد العزيز } \\
& \text { جدة - المملكة العربية السعودية }
\end{aligned}
$$

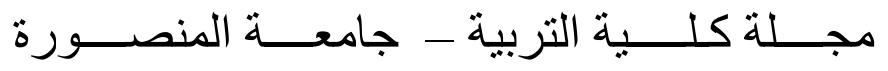

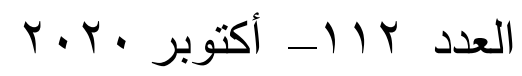

القيادة الأصيلة لاى قادة مدارس التعليم العام بمحافظة ينبع وعلاقتها

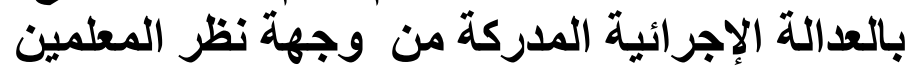




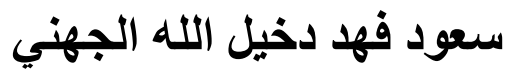

المُقدمة:

تواجه العديد من المنظمات على مستوى العالم في الوقت الراهن صعوبات وتحديات بالغة

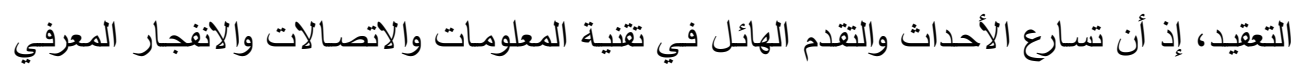

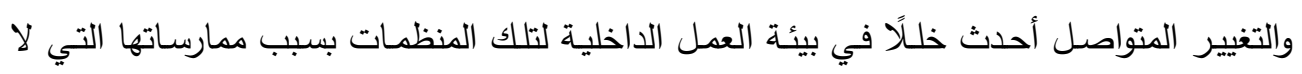
تتكيف مع حجم تلك الأحداث، يضاف إلى ذلك المطالب المجتمعية التي تتادي باستخدام أساليب قيادة ترفع من الفاعلية التظظيمية، من خلال تركيزها على المضامين والأبعاد الأخلاقية في بيئة

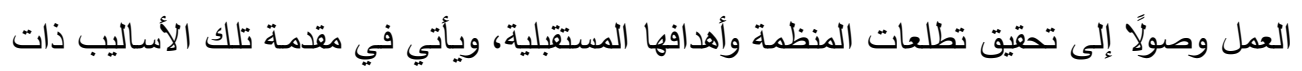
المضامين والأبعاد الأخلاقية أسلوب ونمط القيات القيادة الأصيلة. ويشير أفوليو وجاردنر (Avolio and Gardner, 2005) أن العمل الدؤوب لدى الباحثين

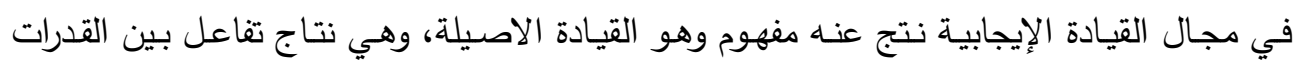

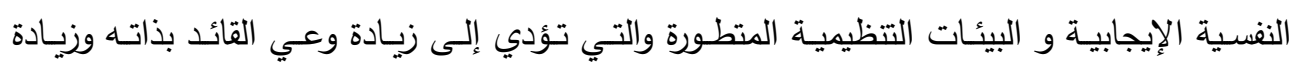

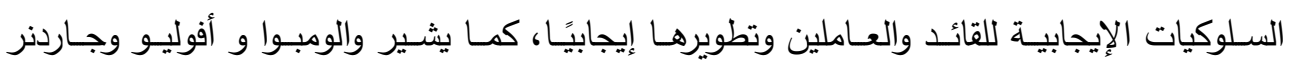

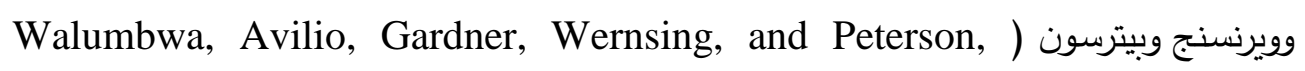
(2008, p94 إلى القيادة الأصيلة أنها نمط من أنماط السلوك يتميز به القائد ومن خلال هذا النمط

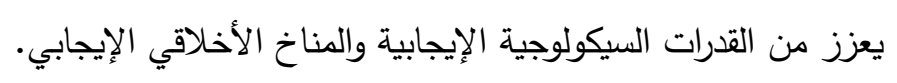

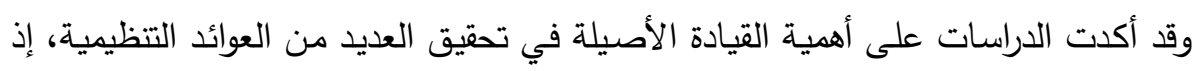

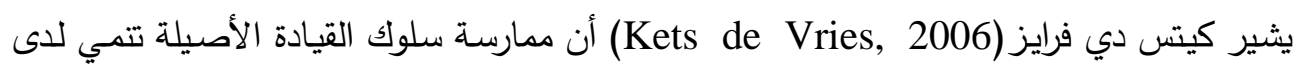

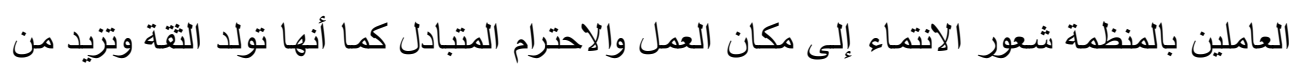
ترابط العاملين وتماسكهم وعن طريقها تتحقق أهداف المنظمة وتزدهر وتجعل من بيئة العمل بيئة عظيمة ورائعة.

وكما هو حال اهتمام المنظمات عامة بأسلوب القيادة الأصيلة، فقد وجد هذا الاهتمام طريقه

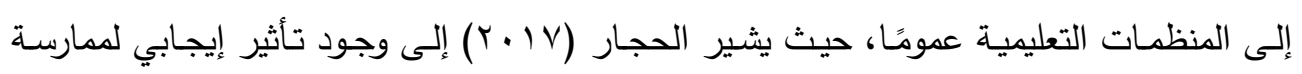

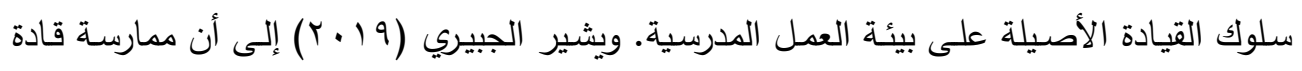
المدارس لسلوك القيادة الأصيلة يرتبط إيجابًا بمستوى دافعية العمل لدى المعلمين داخل المدرسية. 
وأكدت دراسـة سرايفاستافا ودهار (Srivastava \& Dhar, 2019) على التأثير الإيجابي للقيادة الأصيلة لاى قادة المدارس على سلوك الدور الإضافي والتفاؤل الأكاديمي.

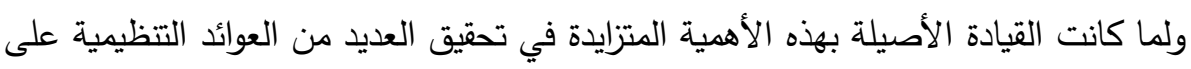

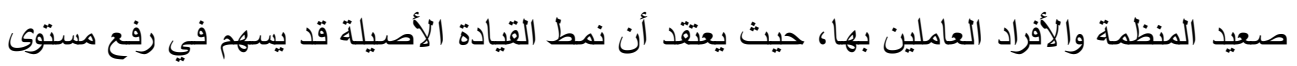

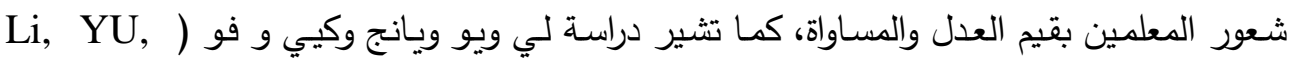
(YANG, QI, and FU, 2014 أكدت دراسة سوقي وسلاميت و اس مارتونو (Sugi, Slamet, S.Martono, 2018) على وجود

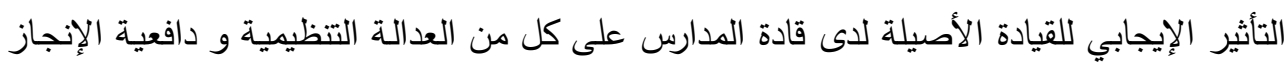

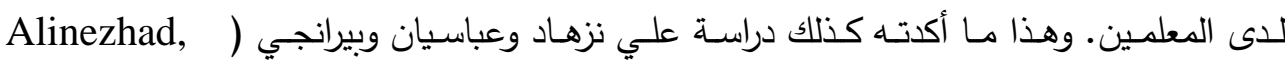
(Abbasian, Behrangi, 2015 إيجابي على كل مـن الالتزام التتظيمي لـى المعلمين ورفـع مستوى الثـعور بالعدالـة التتظيميـة بمدارسهم. ومن جانب آخر تعد العدالة الإجرائية المدركة لدى المعلمين ناتجًا تتظيميًا ذا أهمية حاسمة

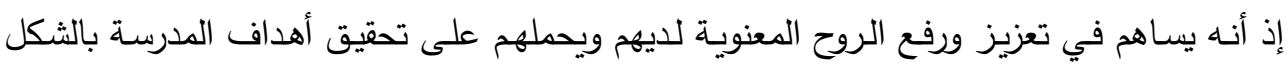

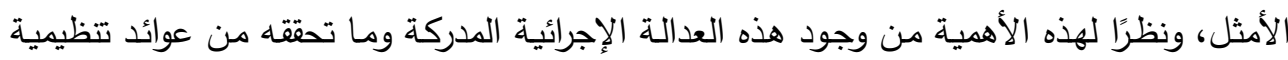
على صعيد المدرسة، يفترض من قادة المدارس تبني أساليب لعمل وترسيخ وتتمية هذه المدركات.

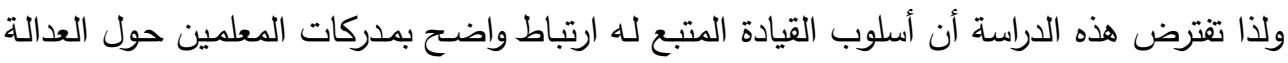

وبنـاء على مـا سبق تتضـح الأهميـة البالغـة لنمط القيادة الأصيلة في ممارسـات القيـادة

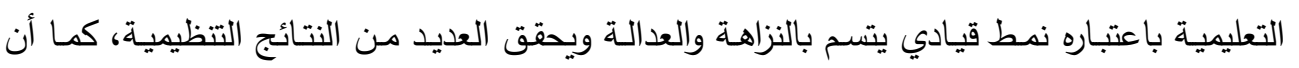
مدارس التعليم العام بحاجة ماسة لرفع مدركات المعلمين حول العدالة لما يساهم ذلك في تحقيق

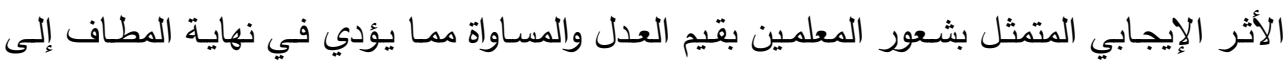
تحقيق أهداف المؤسسة التعليمية على النحو الأمثل، ولهذا تفترض هذه الدئين الدراسة أن لسلوك القيادة

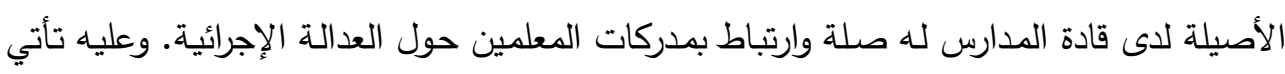
هذه الدراسة للوقوف على طبيعة وحجم العلاقة بين ممارسة قادة المدارس لسلوك القيادة الأصيلة ومستوى العدالة الإجرائية المدركة في مدارسهم. مُشكلة الآّرِراسَةة: 
تواجه المنظمات التعليمية عمومًا والمدارس تحديدًا في المملكة العربية السعودية في الوقت الراهن العديد من المشكلات وأوجه القصور والخلل فيما يتصل بمدركات المعلمين ومشاعرهم حول

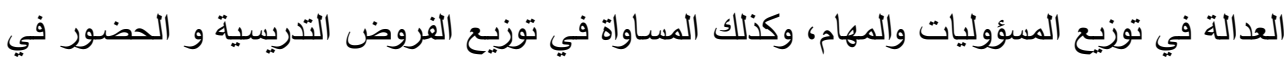

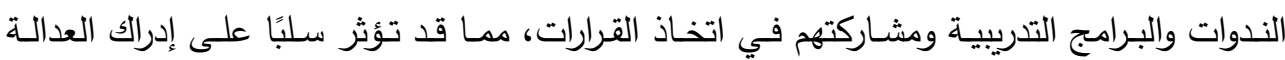

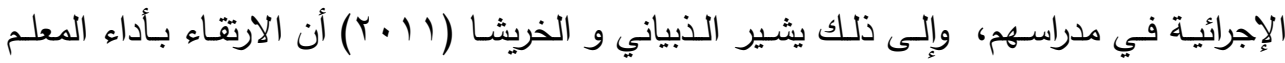

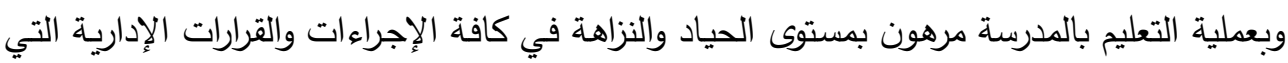

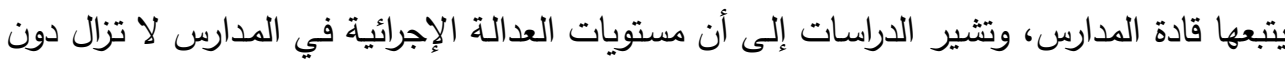

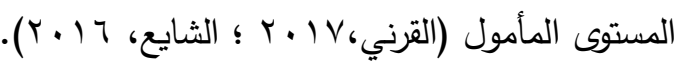

ولذا كان من الأجدر البحث في العوامل والمحددات التي تؤثر في رفع مستويات العدالة الإجرائية المدركة و ربما يكون أسلوب القيادة المتبع في المدرسة أحد تلك العوامل المحددة ، حيث فيث

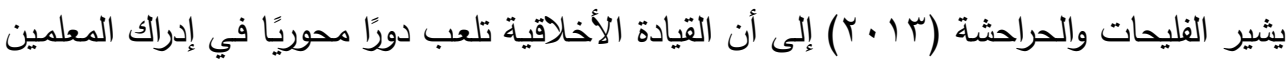

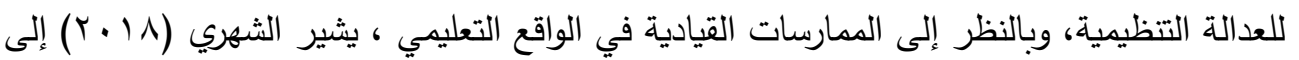

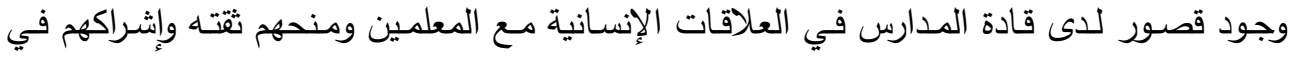

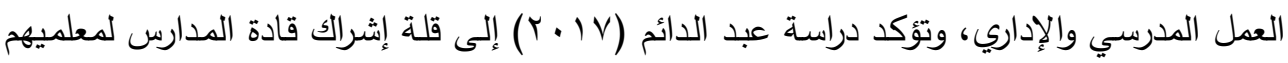

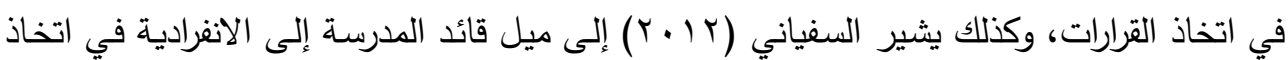
القرارات وعدم إثراك المعلمين في اتخاذه لها أدت بطبيعة الحال إلى تدني شعور المعلمين بمدركات

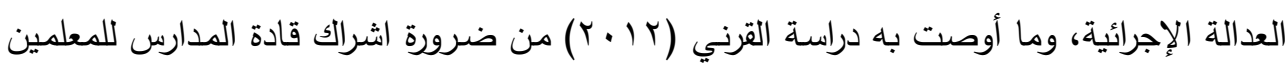

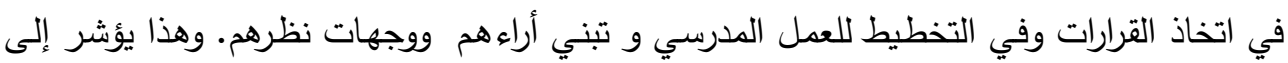

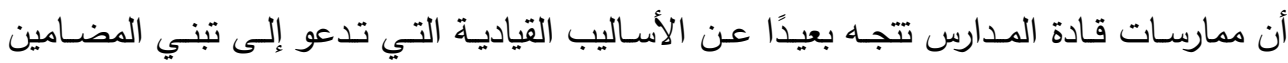

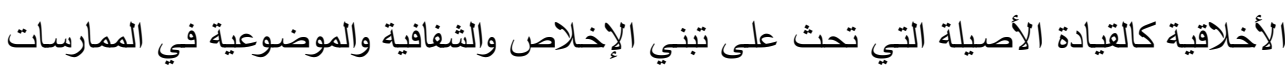
القيادية والذي بدوره يؤثر إيجابًا على المعلمين ويرفع من روحهم المعنوية وينمي لديهم حس الانتماء والولاء للعمل.

ونظرًا لأن عديد من الدراسات أثـارت إلى الأثار الإيجابية لممارسة سلوك القيادة الأصيلة

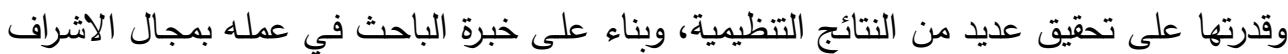
التربوي ووقوفه على الكثير من ممارسات قادة المدارس وملاحظة تدني اشراكهم للمعلمين في اتخاذ

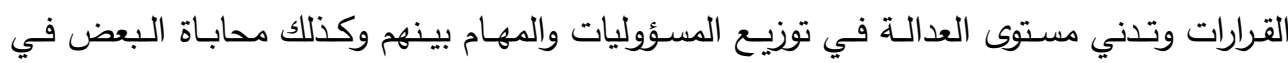
الالتحاق بالدورات والندوات وأيضًا محاباة بعض المعلمين في الحوافز المعنويـة دون البعض الآخر 
أدى إلى تدني الروح المعنويـة لدى المعلمين وأثر على دافعيتهم وانجازهم بشكل ملحوظ وعلى الـى

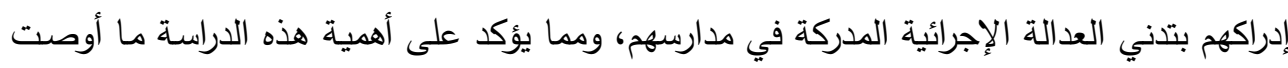

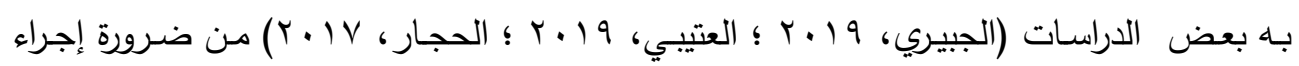

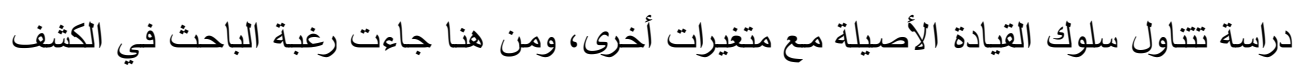
عن طبيعة العلاقة بين ممارسة سلوك القيادة الأصيلة لدى قادة المدارس ومستوى العدالة الإجرائية

$$
\text { المدركة في مدارسهم. }
$$

وعليه تبلورت مشكلة الدراسة الحالية في التساؤل الرئيس التالي: مـا علاقة سلوك القيادة

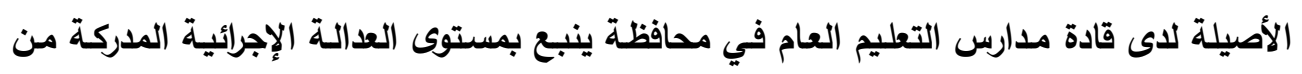

وجهة نظر المعلمين؟

ويتفرع من التساؤل الرئيس للدراسة الأسئلة الفرعية التالية:

•ما درجة ممارسة قادة مدارس التعليم العام في محافظة ينبع لسلوك القيادة الأصيلة من وجهة لألئة

نظر المعلمين؟

•ما مستوى العدالة الإجرائية كما يدركها المعلمون في مدارس التعليم العام في محافظة ينبع؟ •هل توجد فروق ذات دلالة إحصائية بين متوسطات استجابات المعلمين حول درجة ممارسة

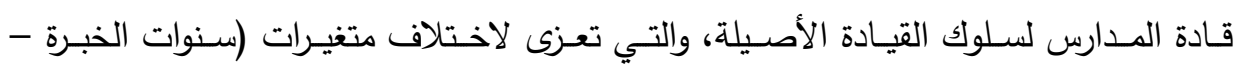
(الجنس)؟ •هل توجد فروق ذات دلالة إحصائية بين متوسطات استجابات المعلمين حول مستوى العدالة

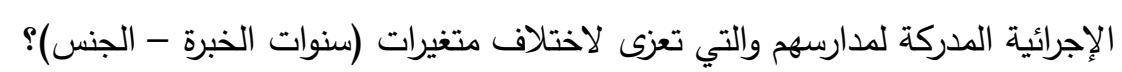

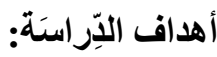
سعت الإِّراسَة الحاليّة إلى تحقيق الأهداف التّاليّة: •التعرف على درجة ممارسة قادة مدارس التعليم العام في محافظة ينبع لسلوك القيادة الأصيلة من وجهة نظر المعلمين. •التعرف على مستوى العدالة الإجرائية كمـا يدركها المعلمون في مدارس التعليم العـام في محافظة ينبع.

•الكشف عن الفروق ذات الدلالة الإحصائية بين متوسطات استجابات المعلمين حول درجة

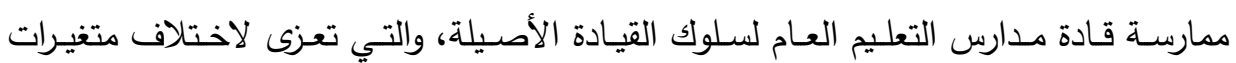

$$
\text { (سنوات الخبرة - الجنس). }
$$


•الكثف عن الفروق ذات الدلالة الإحصائية بين متوسطات استجابات المعلمين حول مستوى

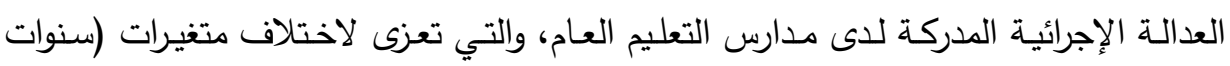

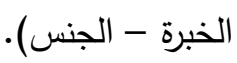

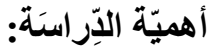

تتجلى أهمية الدراسة كما يلي: •تستمد هذه الدراسـة أهميتها من أهمية موضوع القيادة الأصيلة ومـا تحمله من مزايا وعوائد

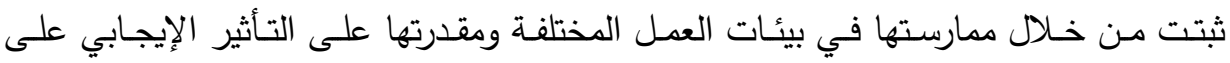

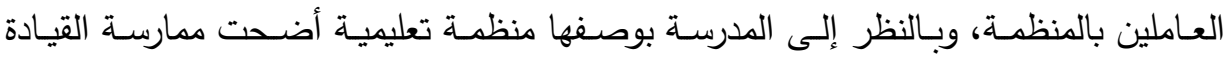
الأصيلة أمرًا ملحًا لما تحققه من عوائد إيجابية لاى المعلمين من رفع مستوى الدافعية لديهم. •كذلك تستمد الدراسة أهميتها من أهمية موضوع العدالة الإجرائية المدركة، إذ أن مستوى هذئه إنهائه

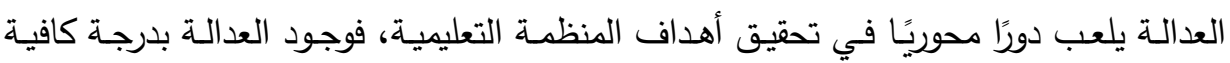
سيسهم في الارتقاء بأداء المعلمين ويعزز من ولائهم للعمل مما تتحقق أهداف المنظمة التعليمية

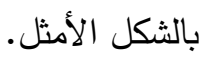
•تستمد هذه الدراسة أهميتها من ندرتها - حسب علم الباحث - حيث تعد الأولى على المستوى

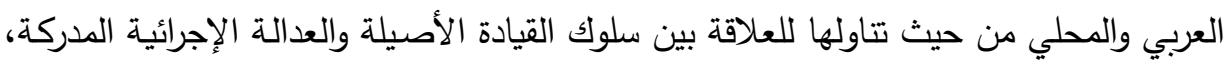
ولذا قد تكون هذه الدراسة ذات قيمة مضافة لاى الباحثين في مجال الإدارة التربوية، إذ قد تقتح لهم آفاقًا أخرى لباحثين آخرين لتناول القيادة الأصيلة وعلاقتها بمتغيرات تلظيمية داتية أخرى.

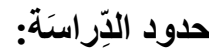

$$
\text { تم تتفيذ هذه الدِرِاسَة في إطار الحدود الآتية: }
$$

•الددود الموضوعية: ستقتصر الحدود الموضوعية للدراسة على محورين هما: المحور الأول الدئل القيادة الأصيلة بأبعادها التالية: (الوعي الذاتي، المفهوم الاخلاقي الداخلي، الدعالجة المتوازنة، شفافية العلاقات). المحور الثاني العدالة الإجرائية المدركة كأحد أبعاد العدالة التنظيمية. •الحدود المكانيـة: ستقتصـر تطبيق هذه الدراسـة على مدارس التعليم العام (بنين - بنـات) الحكومية في محافظة ينبع. •الحدود البشرية: ستقتصر هذه الدراسة على معلمي ومعلمات مدارس التعليم العام الحكومية. •اكـدود الزمنيـة: سيتم تطبيق هذه الدراسة خـلال الفصل الدراسي الثاني من العام الدراسي 


\section{القيادة الأصيلة: - n}

يعرفها والومبوا وآخرون (Walumbwa et al.,2008) بأنها: نمط سلوك يمارسه القائد

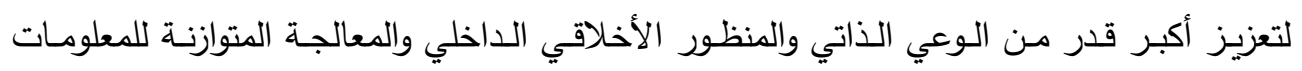
والثفافية وتعزيز التتميـة الذاتيـة الإيجابيـة مـن خـلال توظيفهـ للقدرات النفسية الإيجابيـة للعاملين

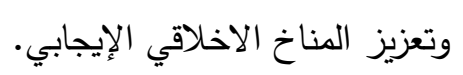
ويعزّفها الباحث إجرائيًا بأنها: نمط من أنماط السلوك القيادي الذي يستخدمه قائد الددرسة

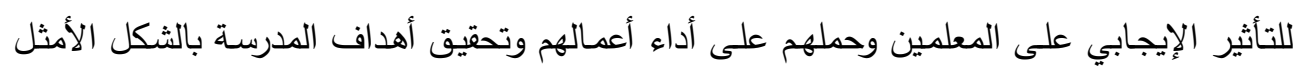
من خلال تعزيز الوعي الذاتي وتبني المفهوم الأخلاقي الداخلي في التعامل مع المعلمين واستخدام التوازن في المعالجة وترسيخ مفهوم الثفافية في العلاقات مع المعيز المعلمين.

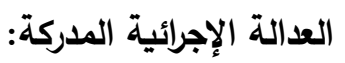

يعرف مورمـان (Moorman, 1991) العدالـة الإجرائية بأنها شعور الموظفين بإنصـاف وعدالة الاجراءات المستخدمة من قبل المنظمة في تحديد النتائج والمخرجات. ويعزّفها الباحث إجرائيًا بأنها: بقدرة قائد المدرسة على تلى توفير بيئة تعليمية جاذبة من خلاد تحقيق مبدأ العدالة في توزيع المسؤوليات والمهام بين المعلمين وتحقيق المساواة في الالتحاق ببرامج

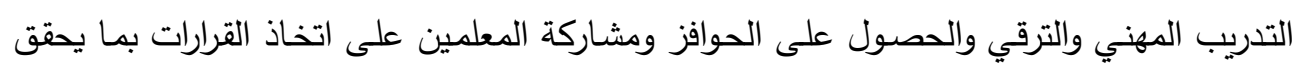
أهداف المدرسة على النحو الأمثل.

أولًا: الإطار النظري: قُّبّم الإطار النظري إلى مبحثين: المبحث الأول: القيادة الأصيلة، وتتاول المبحث الثّاني: العدالة الإجرائية المدركة. المبحث الأول: القيادة الأصيلة:

مفهوم القيادة الأصيلة: - م الاول: إن التعريف الاصطلاحي للقيادة الأصيلة مر بفترات مختلفة نتيجة لاختلاف الباحثين الذين

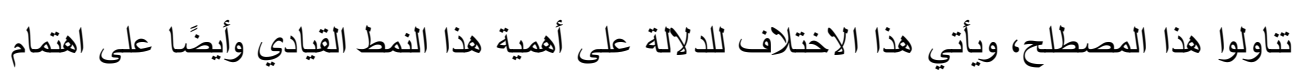

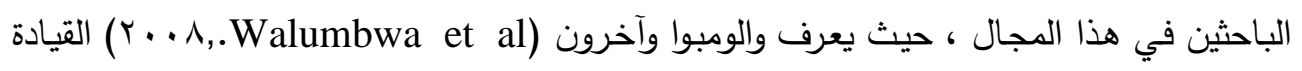

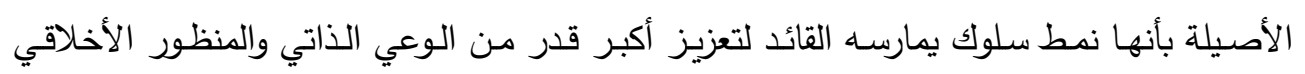


الداخلي والمعالجة المتوازنة للمعلومات والثفافية وتعزيز التتمية الذاتية الإيجابية من خلال توظيفه للقدرات النفسية الإيجابية للعاملين وتعزيز المناخ الاخلاقي الإيجابي. ويعرف لوثنز وأفوليو (Avolio, 2003 \& Luthans) القيادة الأصيلة بأنها العملية التي التياتي تتنج عن طريق التفاعل بين القدرات النفسية الإيجابية والبيئات التنظيمية المتطورة، والتي تنتهي

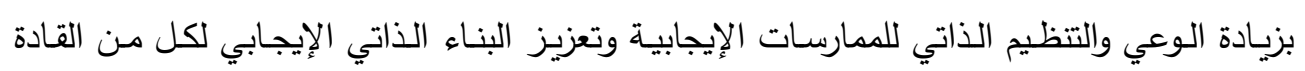

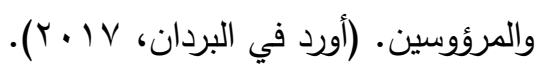

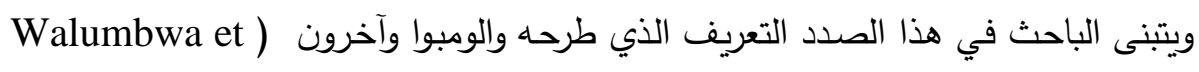

(al.,2008) ، والذي يحتوي - بحسب وجهة نظر الباحث - على الأبعاد الأربعة للقيادة الأصيلة

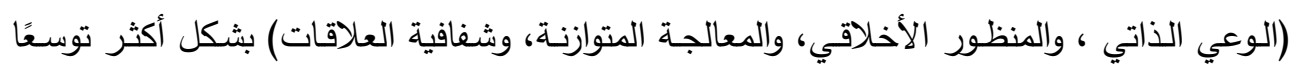
وشمولية عن غيره من التعريفات، وعليه يعرف الباحث القيادة الأصيلة في السياق المدرسي: والثية وأنها

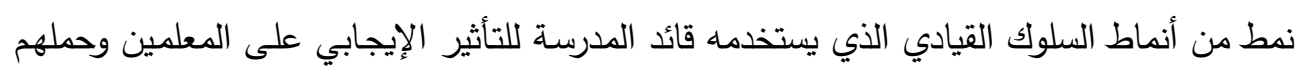

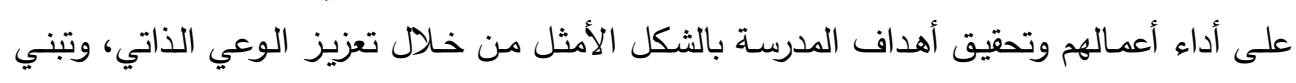
المفهوم الأخلاقي الداخلي في التعامل مع المعلمين، واستخدام التوازن في المعالجة وترسيخ مفهوم الثفافية في العلاقات مع المعلمين.

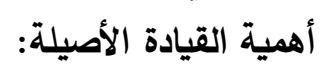

تلعب القيادة دورًا مهمـا في نجاح أو فثل المنظمـة، وفي مدى تحقيقها لأهدافها بالثكل

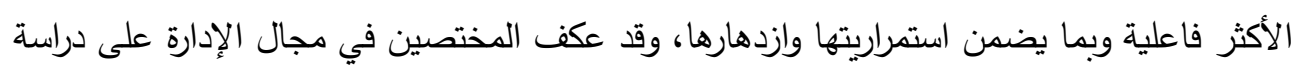

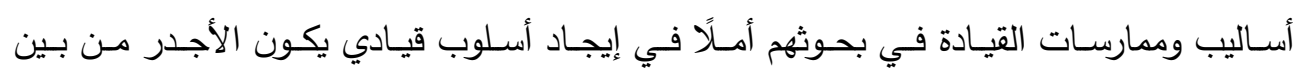

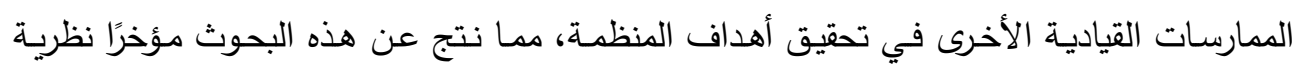

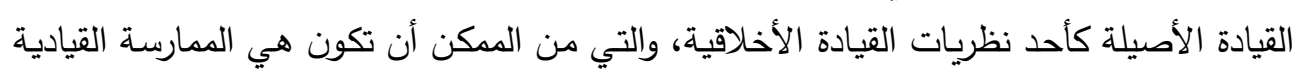
المرجوة من قبل هؤلاء المختصين في علم الإدارة. ويعتقد بأن القيادة الأصيلة وما تتضمنه من جواءنب إيجابية تمثل الأسلوب الأمثل لإصدلاح

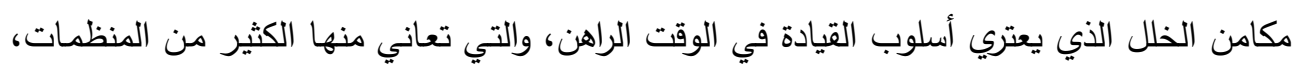

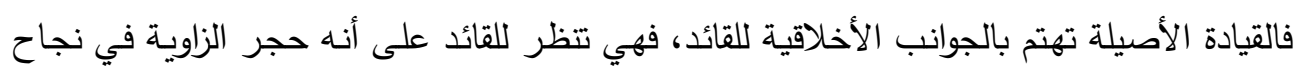
المنظمة، والذي قد يكون بيده مفتاح نجاحها وازدهارها أو العكس.

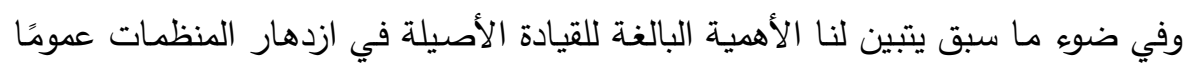
وفي الددارس خصوصًا، ويجب على قادة المدارس أن يعيدوا النظر في ممارساتهم القيادية الحالية 
وأن يتبنوا نمط القيادة الأصيلة لما لها من أثر بالغ في تعزيز الروح المعنوية للمعلمين، وأيضًا تعزيز انتمائهم للمدرسة مما ينعكس إيجابًا على تحقيق أهداف المدرسة بالثكل الأمثل.

أبعاد القيادة الأصيلة:

تختلف الدراسـات السـابقة عن بعضـها البعض في تتـاول أبعـاد القيادة الأصيلة، فأغلب

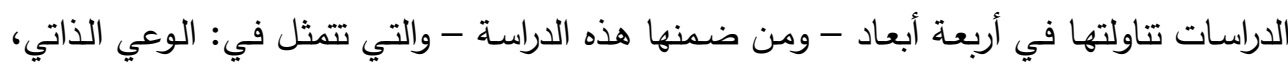

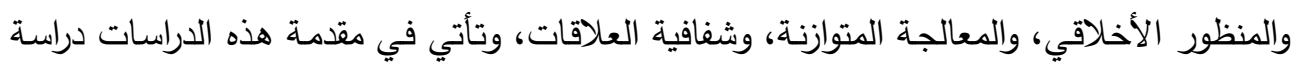

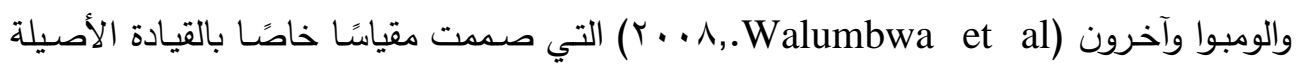
المشتمل على الأبعاد الأربعة السابقة.

كذلك كانت هناك دراسات تتاولت القيادة الأصيلة بأكثر من أربعة أبعاد كدراسة الحجار

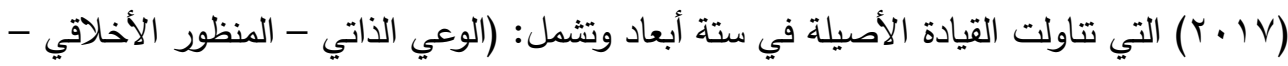
شفافية العلاقات - المعالجة المتوازنة - الحب - الانضباط الذاتي).

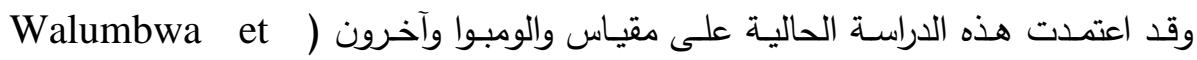

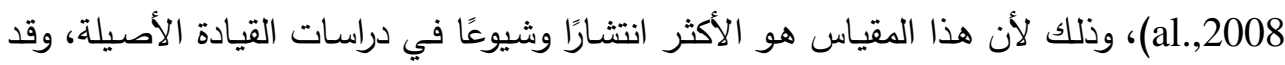

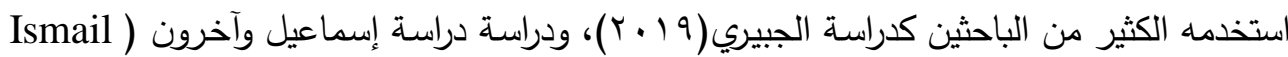

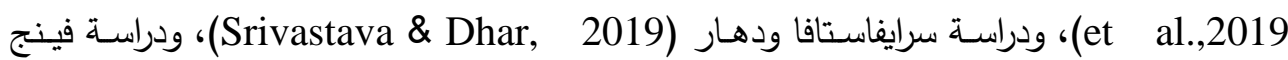

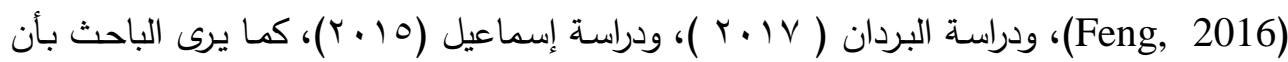

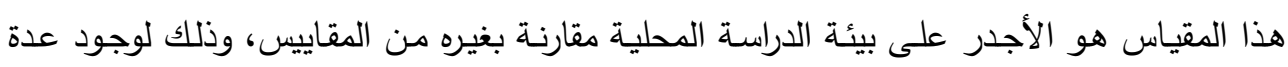

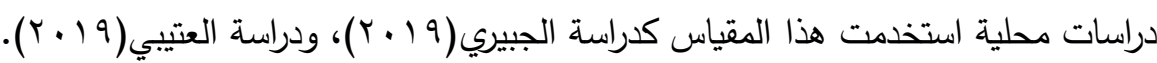
وسنستعرض فيما يلي الأبعاد الأربعة لهذا المقياس. أولاً: الوعي الذاتي:

يعد الوعي الذاتي البعد الأول للقيادة الأصيلة، حيث يثير لوثنز وأفوليو (Avuthans)

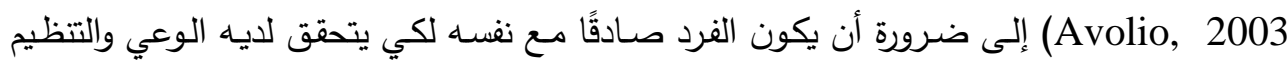
الذاتي، حيث يستطيع القائد الأصيل اكتساب الوضوح بذاته وهويته وقيمته وأهدافه وعواطفه ودوافعـه لـانه

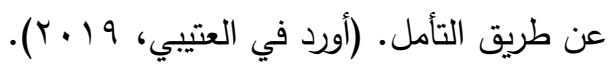
ثانيًا: المنظور الأخلاقي الذاتي: 


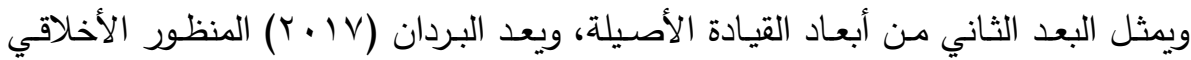

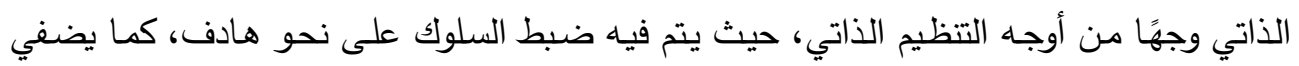

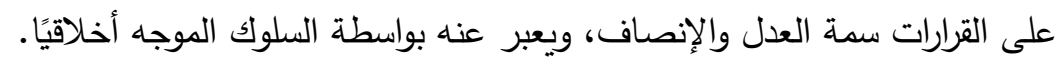

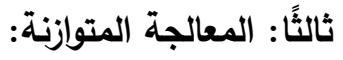

تعد المعالجة المتوازنة البعد الثالث من أبعاد القيادة الأصيلة والتي يعرفها والومبوا وآخرون

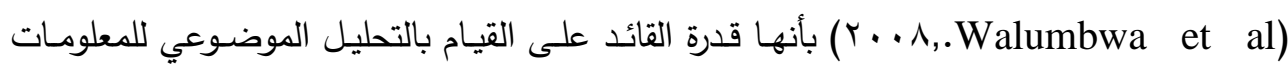

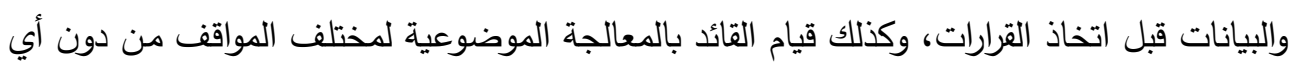

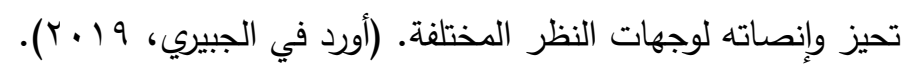

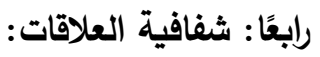

ويعــــــا البعـد الرابـع والأخيـر مـن أبعـاد القيــادة الأصـيلة، ويعـرف والومبـوا وآخـرون

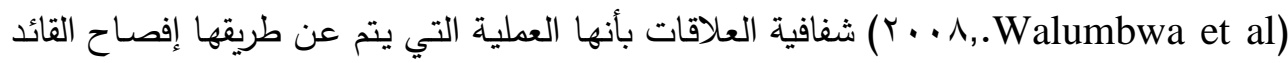

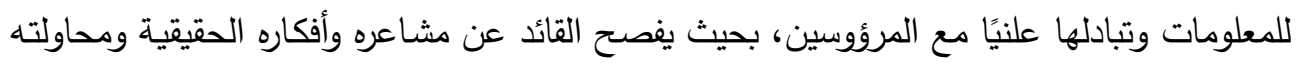
التخفيف من المشاعر السلبية من أجل تعزيز التقة بينه وبين المرؤوسين. سمات وخصائص القائد الأصيل:

إن للقائد الأصيل سمات وخصائص تميزه عن غيره من القادة الأمر الذي من شأنه أن يؤثر الأثيل:

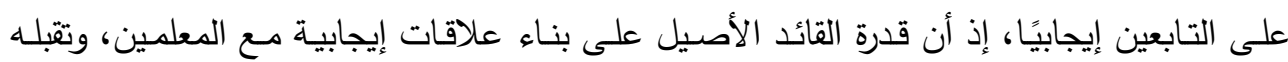
لآرائهم حتى لو اختلفت مع رأيه، وكذلك تميزه بالنزاهة والموضوعية عند اتخاذه للقرارات، هي أهم ما

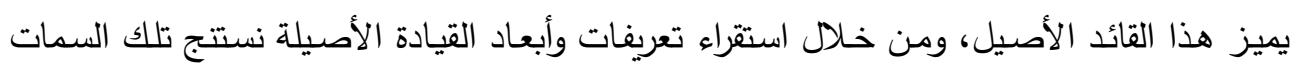
والخصائص.

وهناك بعض الأدبيات التي تتاولت خصائص القائد الأصيل، حيث يؤكد جاردنر وآخرون

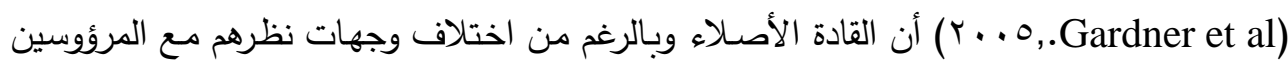

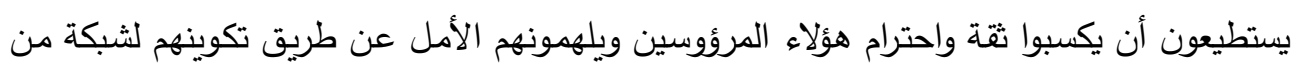

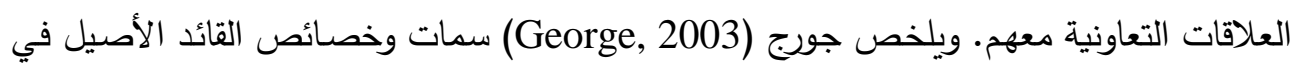
خمس سمات وهي: امتلاكه الثغف بالهدف الذي يسعى لتحقيقه، وقدرته على بناء علاقات قوية مع الآخرين، وتميزه بالصدق مع القيم التي يتبناها ويؤمن بها، وتميزه بالانضباط الذاتي، وينمي مشاعره العاطفية تجاه الآخرين. المبحث الثاني: العدالة الإجرائية: 


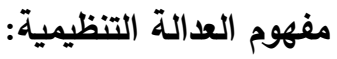

تتعدد التعريفات التي تتاولت مفهوم العدالة التظظيمية في مختلف الأدبيات العلميـة، وهذا

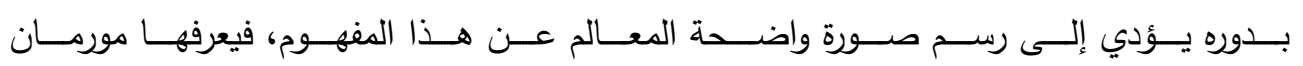
(Morman,1991,p845)

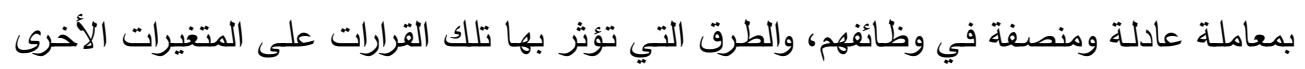
المتعلقة في بيئة العمل".

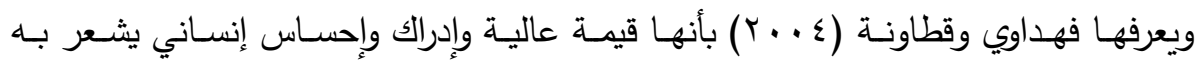

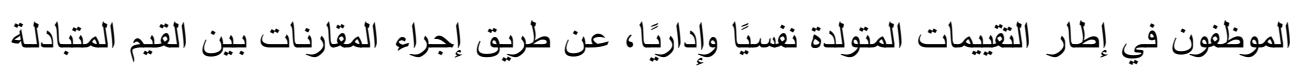
بين الموظفون وإدارة المنظمة.

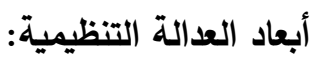

قسم نيهوف ومورمان Moorman, 1993 \& Niehoff) العدالة التظظيمية إلى ثلاثة أبعاد

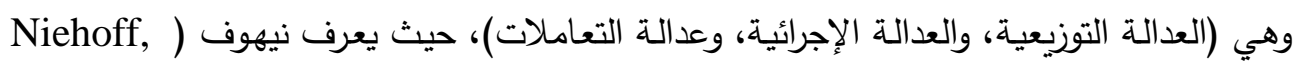

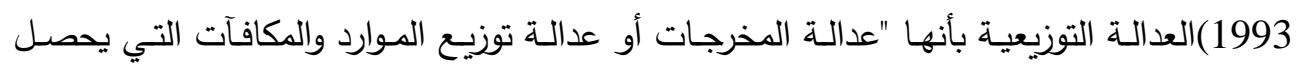

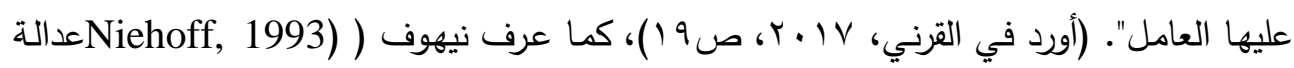
التعاملات بمدى شعور وإحساس العامل بعدالة المعاملة التي يحصل عليها إزاء تطبيق الإجراءات

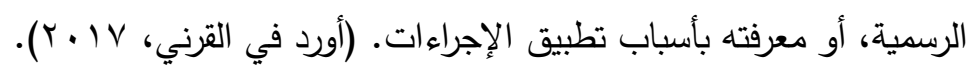
ولقد صمم نيهوف ومورمان Moorman, 1993 \& Niehoff) ) وفقًا لهذا التقسيم مقياسًا يعتبر الأكثر استخدامًا وشيوعًا في الدراسات التي تتاولت مفهوم العدالة التظظيمية بأبعاده الثلاثة

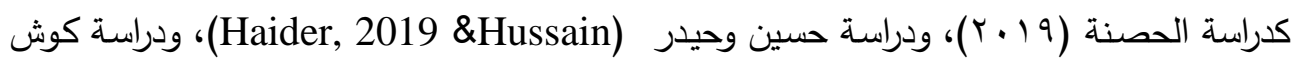
وأزون (Uzun, 2018 \& Kose)، وبناء على وجود دراسات محلية تتاولت مفهوم العدالة التنظيمية

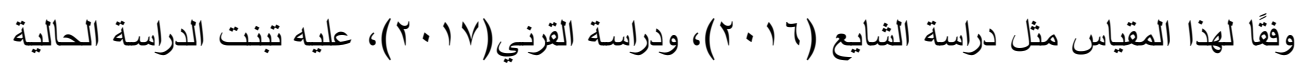
هذا المقياس في بعد العدالة الإجرائية كأحد أبعاد العدالة التظيمية.

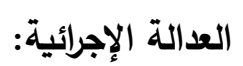

يتعلق هذا المفهوم بمدى إدراك الموظفين لعدالة الاجراءات التي تتخذ من قبل إدارة المنظمة تجاههم، وتنص على أنه كلما زاد إدراك الموظفين لعدالة الإجراءات كلما زاد لديهم الثعور بالالتزام والرضا الوظيفي. 
وقد عرف مورمان (Moorman, 1991) العدالة الإجرائية بأنها شعور الموظفين بإنصاف وعدالة الاجراءات المستخدمة من قبل المنظمة في تحديد النتائج والمخرجات.

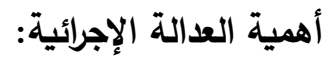

تعـد العدالـة الإجرائيـة أحـد أبعـاد العدالـة التتظيميـة التـي تهـتم بمدركات المعلمين لعدالـة الإجراءات المستخدمة في بيئة العمل المدرسية، والتي تتمثل في تطبيق تلك الإجراءات على كافة

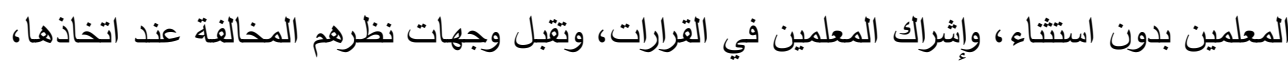

وتزويدهم بالمعلومات الدقيقة المرتبطة بالقرارات عند استفسارهم عنها. ومن جهة أخرى تؤدي العدالة الإجرائية إلى تحقيق السيطرة الفعلية، والتمكن في اتخاذ القرار

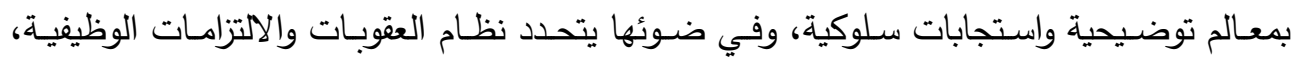

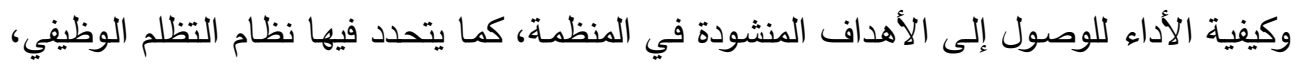

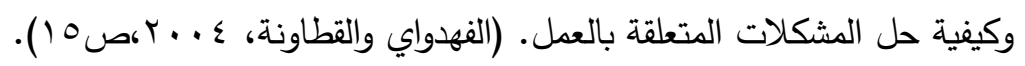

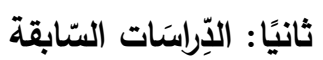
الاراسات التي تناولت متغير القيادة الأصيلة: أجرى الجبيري (9 ( + ؟) دراسة هدفت للكثف عن العلاقة بين القيادة الأصيلة لدى قادة المدارس المتوسطة بمحافظة الليث بدافعية العمل لدى المعلمين، ولتحقيق أهداف الدراسة استخدم الباحث أسلوب المنهج الكسي بشقيه (المسحي والارتباطي)، واعتمد الباحث على مقياس والمبوا

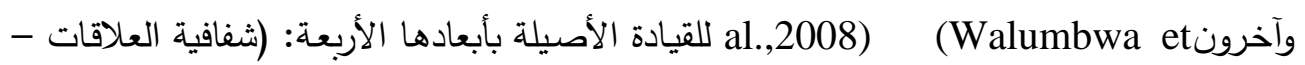
المنظور الأخلاقي الذاتي - الوعي الذاتي - المعالجة المتوازنة)، واستبيانًا لدافعية العمل بأبعادها

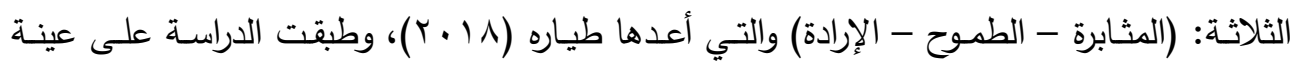

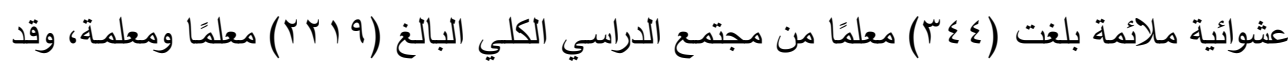

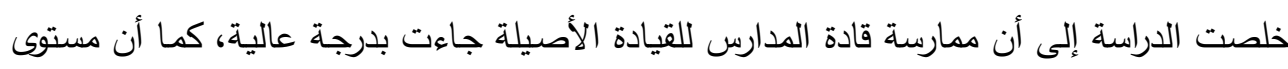

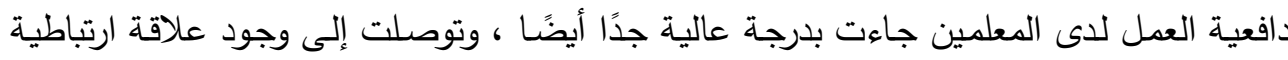
طرديـة متوسطة القيمـة وذات دلالـة احصـائية بين درجـة ممارســة قادة المـارس للقيـادة الأصيلة

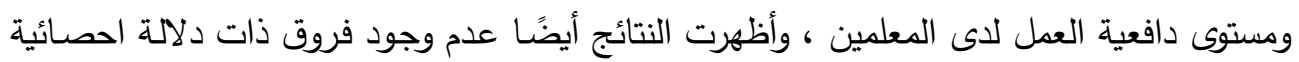

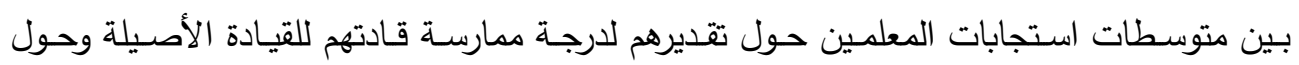
تقديرهم لمستوى دافعية العمل لديهم تعزى إلى اختلاف متغيري (الجنس - سنوات الخبرة) ، كما أوصت بإجراء المزيد من الدراسات حول القيادة الأصيلة وربطها مع متغيرات أخرى. لألئ. 
وفي السياق ذاتـه أجرى العتيبي (19 • ب) دراسـة هدفت إلى التعرف على درجة ممارسـة

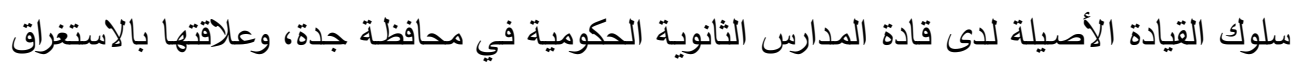

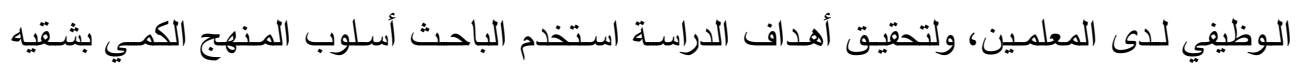

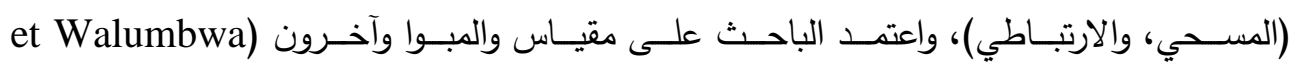

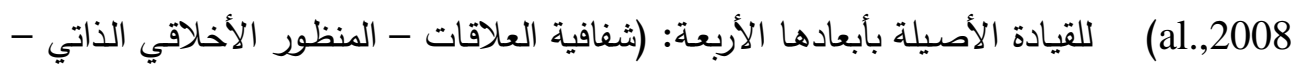

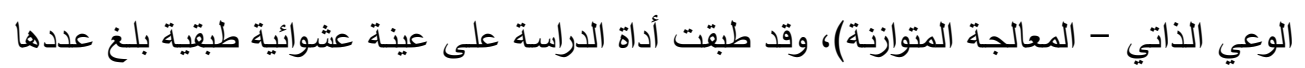

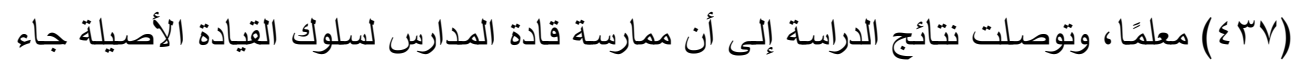

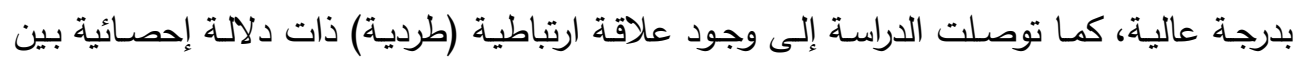
ممارسة سلوك القيادة الأصيلة لقادة المدارس ومستوى الاستغراق الوظيفي للمعلمين.

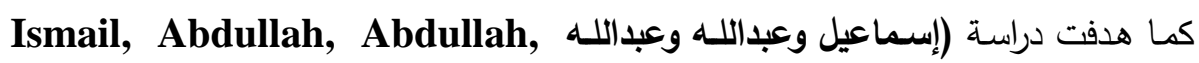

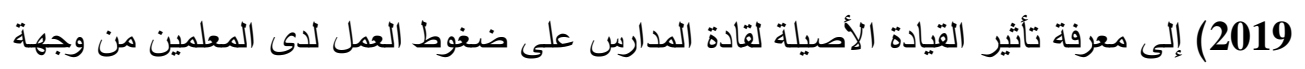

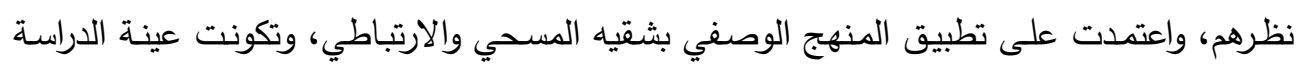

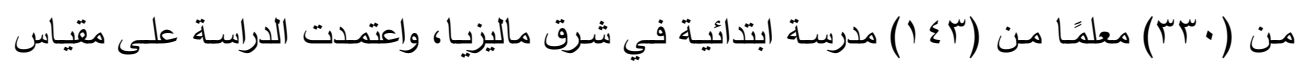

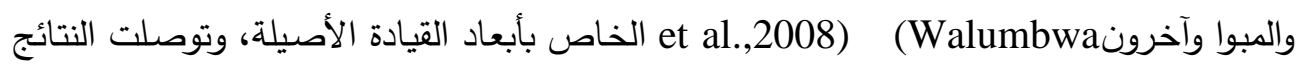

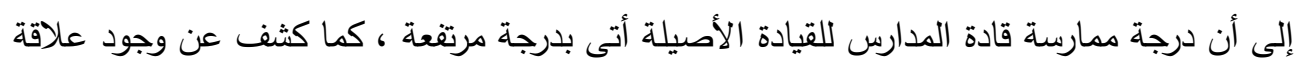

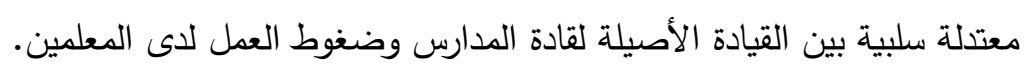
الإِراستَات التي تتاولت متغير العدالة الإجرائية المدركة: في هذا المحور سيتم تتاول العدالة الإجرائية المدركة كأحد أبعاد العدالة التنظيمية من خلاد التهاليه استعراض الدراسات السابقة المتعلقة بهذا المتغير والتي اطلع عليها الباحث.

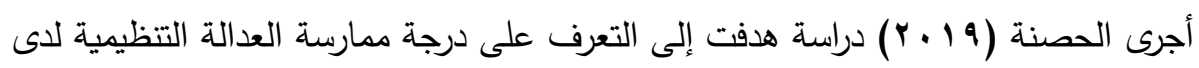
قادة المدارس بمحافظة بيشة و علاقتها بالولاء التتظيمي من وجهة نظر المعلمين، واستخدم الباحث

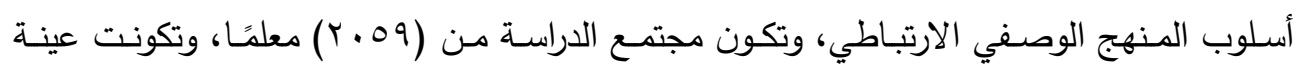

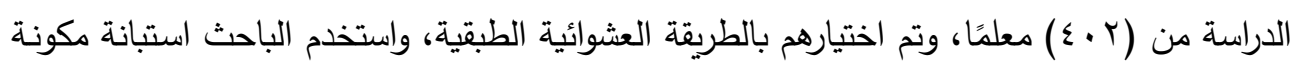

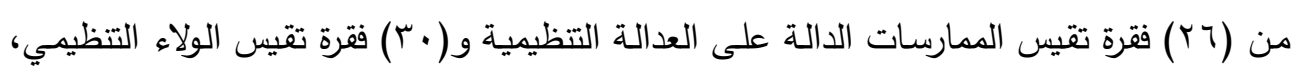

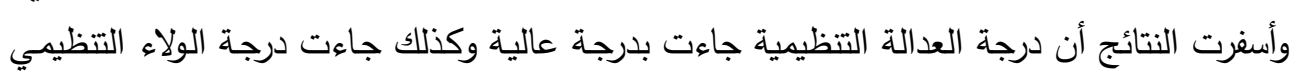
بدرجة عالية. 
كما هدفت دراسة حسين وحيدر (Haider, 2019 \&Hussain) إلى التعرف على دور العدالة التتظيمية في التتبؤ بأداء المعلمين في المدارس الخاصة والعامة في ولاية البنجاب بباكستان،

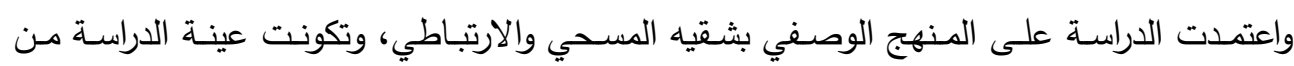

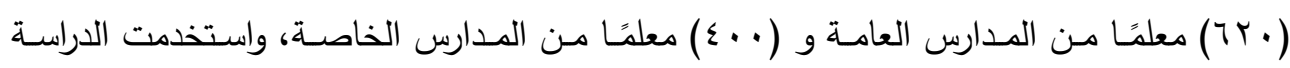

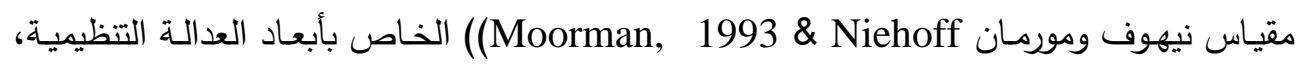
وتوصلت النتائج إلى وجود تأثير إيجابي كبير للعدالة التتظيمية على أداء المعلمين. وهدفت دراسـة كـوش وأزون (Uzun, 2018 \& Kose) إلى الكثف عن إلى العلاقـة بين العدالة التظيمية والاستغراق الوظيفي لدى المعلمين، واعتمدت الدراسة على المنهج الوصفي بشقيه

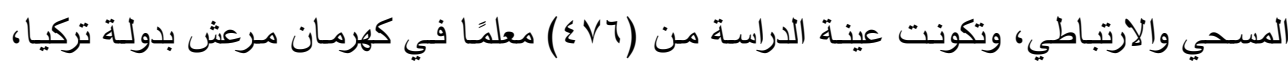

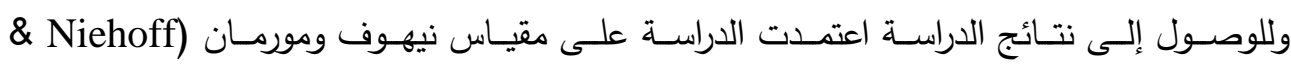
(Moorman, 1993 إيجابية بين العدالة التتظيمية وإشراك العمل لدى المعلمين. التعقيب على الآّراسَتات اللسّابقة:

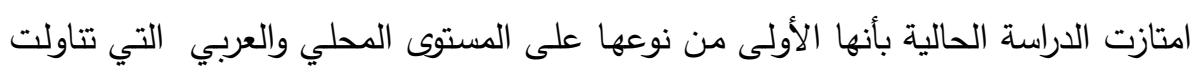

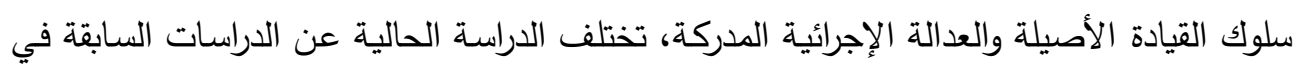
مواضيع عدة، حيث اكتسبت هذه الدراسـة أهمية وميزة تميزهـا عن غيرهـا، فهذه الدراسـة الحاليـة تتصف بأنها نادرة محليًا وعربيًا - على حد علم الباحث - في تتاول متغير العدالة الإجرائية تحديدًا

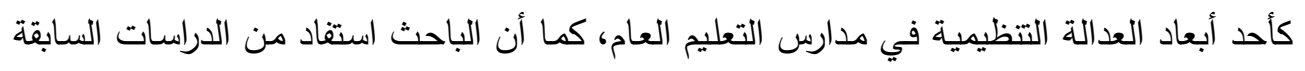

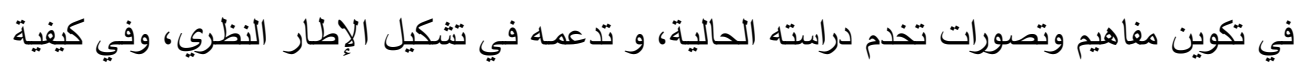
بناء أداة الدراسة وتفسير النتائج وتحليلها.

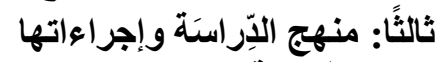

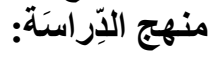

لتحقيق أهداف الدراسـة استخدم الباحث المنهج الكمي (Quantitative Approach) بشقيه المسحي، والارتباطي لكون هذا الأسلوب الأكثر ملاعمة لطبيعة الدراسة. مجتمع الآّراستَة: يتكون مجتمع الدراسة من جميع معلمي ومعلمات مدارس التعليم العام بمحافظة ينبع والبالغ

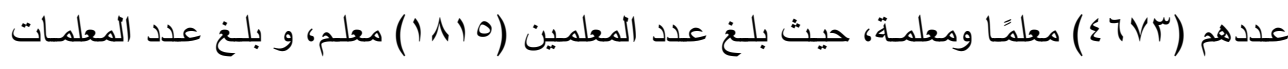




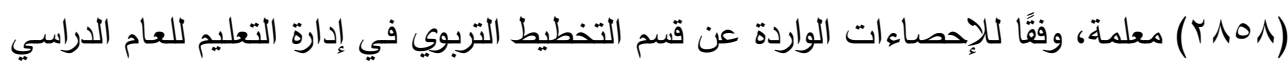

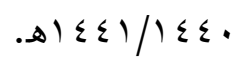
عيّنة الإِّراستة:

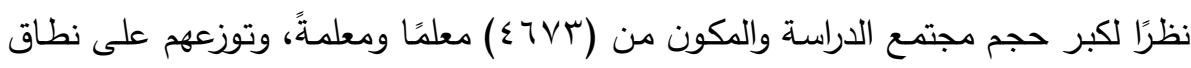
جغرافي كبير ، حيث إن بعضهم يتواجد في قرى وهجر متباعدة فيما بينها مما يصعب معده إجراء

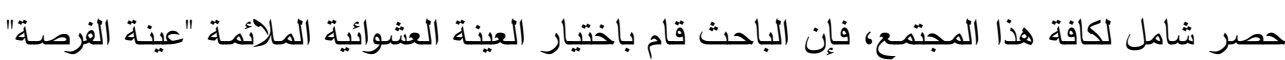

(Conveniece Sample)

وقد قام الباحث بتصميم الاستبانة على (Google Drive) وتوزيعها إلكترونيًا على أفراد

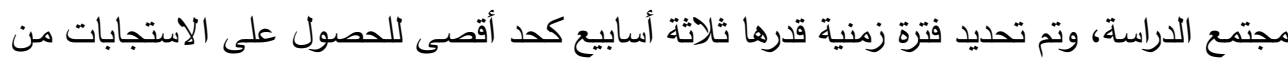

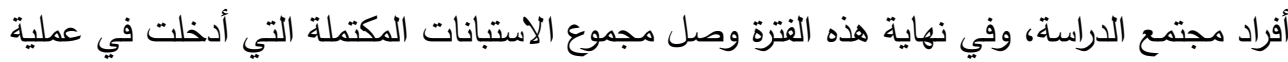

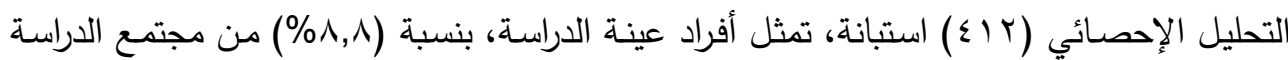
وصف عيّتة الإّراسَة: تم حسـاب التكرارات والنسب المئويـة لأفراد عينـة الدراسـة وفقاً للمتغيرات (الجنس، سنوات

$$
\text { الخبرة في التعليم)، كما يلي: }
$$

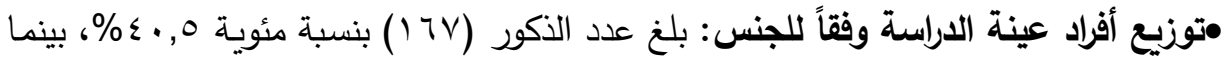

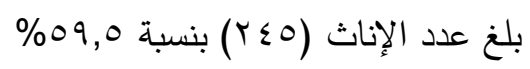

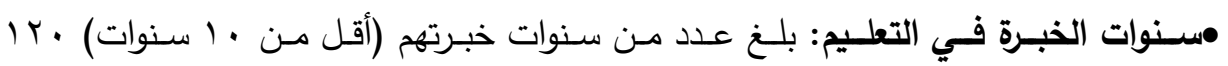

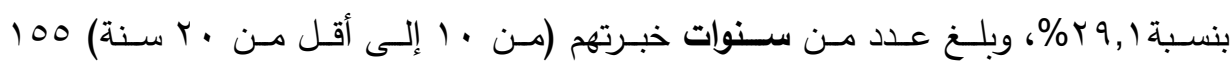

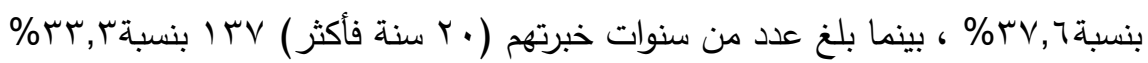

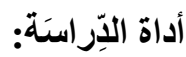

اعتمد الباحث في بناء المحور الأول من الاستبانة والذي سعى للتعرف على (درجة ممارسة

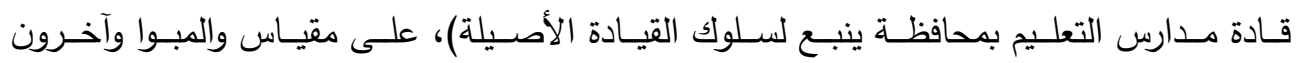
(Walumbwa et al,2008)

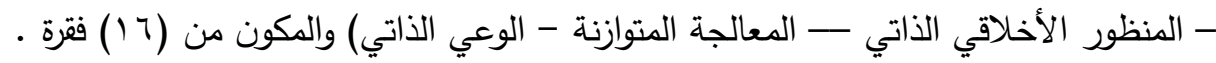
أمسا فيما يخص المحور الثاني والذي هدف إلى التعرف على مستوى العدالة الإجرائيـة

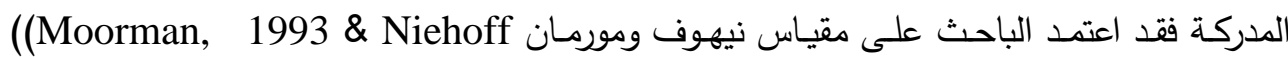


للعدالـة الإجرائيـة كأحد أبعاد العدالـة التتظيميـة، وتتكون الاستبانة مـن (†) فقرات. ولقد احتوت الاستبانة على جزءين رئيسيين هما:

الجُزء الأوّل: البيانات الثخصية لأفراد عينة الدراسة وتمثلت في (الجنس، سنوات الخبرة في

الجزء الثاني: محاور الاستبانة، وتكون من محورين رئيسيين هما:

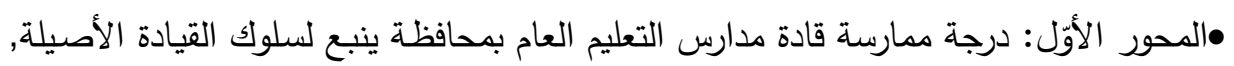

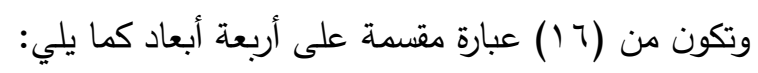

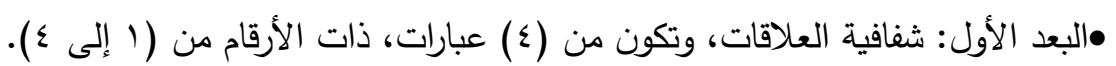

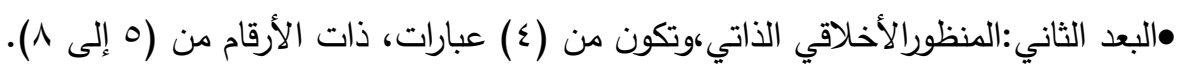

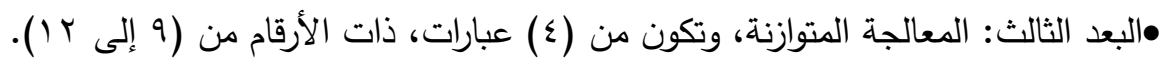

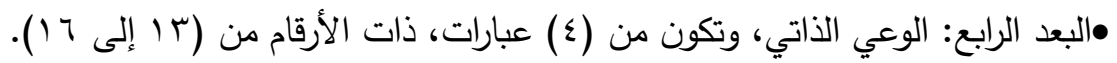

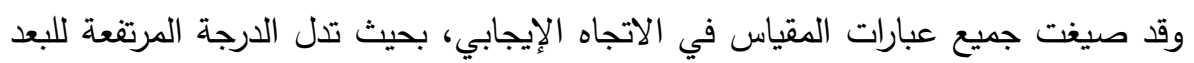

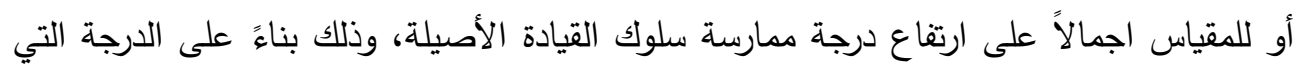

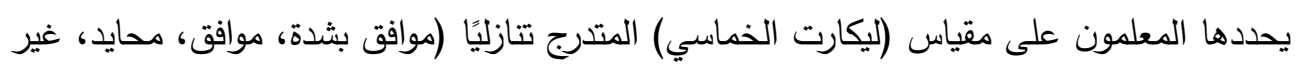
موافق، غير موافق بثدة).

•المحور الثاني: مستوى العدالة الإجرائية في مدارس التعليم العام بمحافظة ينبع كما يدركها

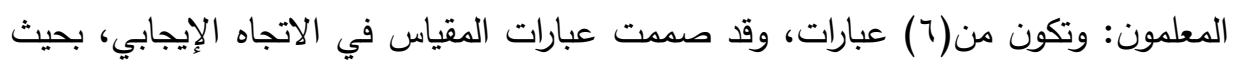

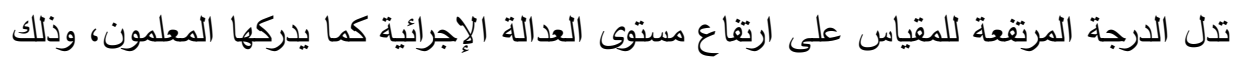
وفقًا للدرجة التي يختارها المعلمون على مقايس ليكارت الخماسي (موافق بشدة، موافق، محايد، غير موافق، غير موافق بثدة).

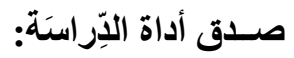

للتحقّق من صدق أداة الذِّراسَة تََّّ قياس كلُ من:

$$
\text { •صدق الاتساق الاخلي: }
$$

•صدق الاتساق الداخلي للمحور الأول (درجة ممارسة قادة مدارس التعليم العام بمحافظة

\section{ينبع لسلوك القيادة الأصيلة):}

تم حسـاب صدق الاتسـاق الداخلي بحساب معامل ارتباط بيرسون بين درجات كل عبارة

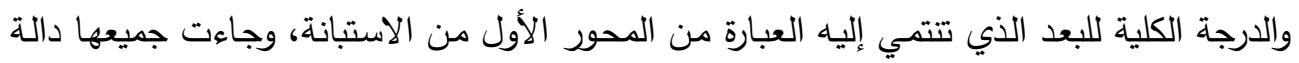




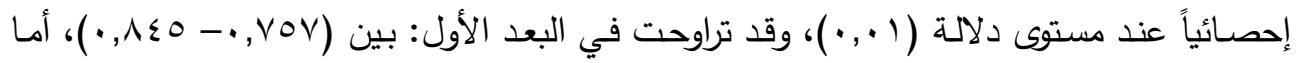

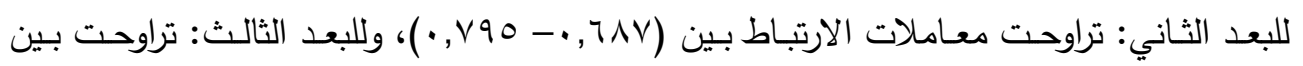

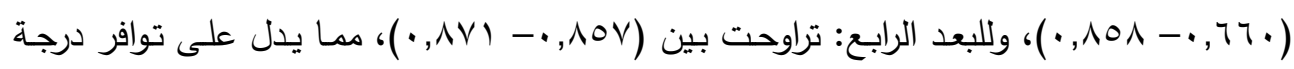
عالية من صدق الاتساق الداخلي للدحور الأول من الاستبانة (درجة ممارسة قادة مدارس التعاد التعليم العام بمحافظة ينبع لسلوك القيادة الأصيلة).

•الصدق البنائي للمحور الأول (درجة ممارسة قادة مدارس التعليم العام بمحافظة ينبع

لسلوك القيادة الأصيلة)

تم التحقق من الصدق البنائي للدحور الأول من خلال إيجاد معاملات الارتباط بين الدرجة

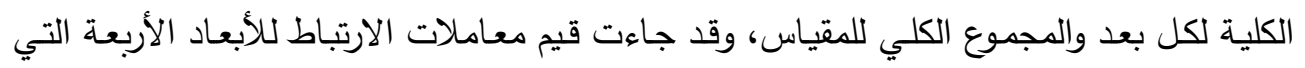

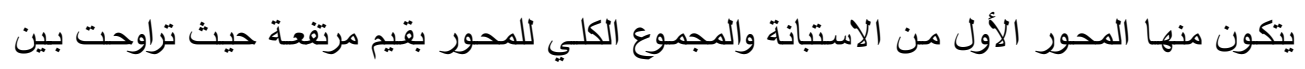

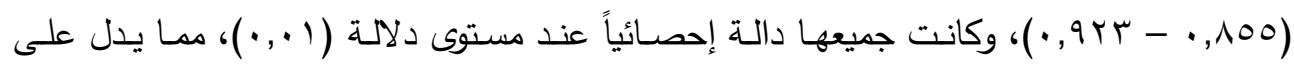
توافر درجة عالية من الصدق البنائي للدحور الأول من الاستبانة (درجة ممارسة قادة مدارس التعليم العام بمحافظة ينبع لسلوك القيادة الأصيلة). r) صدق الاتساق الداخلي للمحور الثاني (مستوى العدالة الإجرائية في مدارس التعليم العام بمحافظة ينبع كما يدركها المعلمون)

تم حساب صدق الاتساق الداخلي بحساب معامل ارتباط بيرسون بين درجات كل عبارة

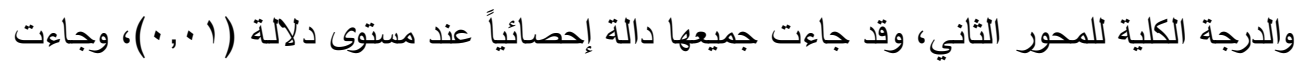

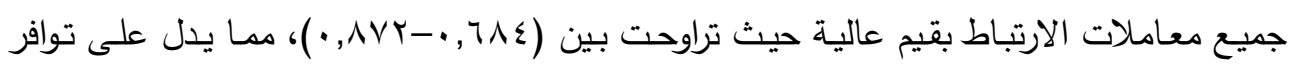

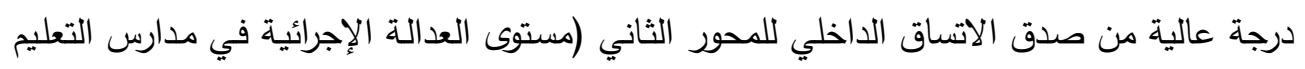

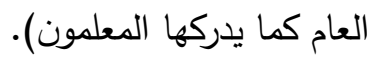

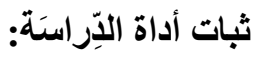

تم التأكد من ثبات الاستبانة من خـلال حساب ثبات الاتساق الداخلي للعبارات باستخدام

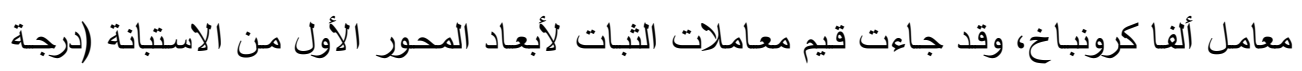

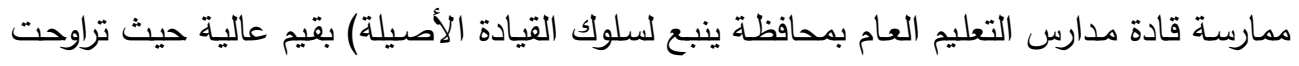

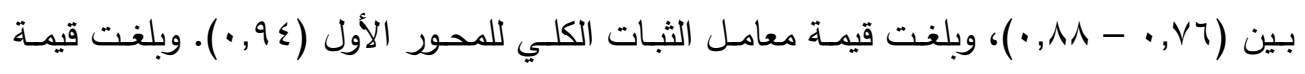

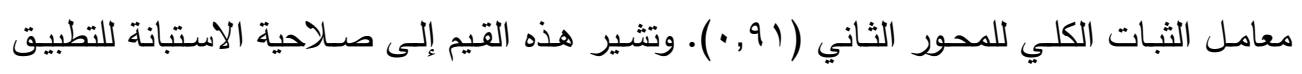

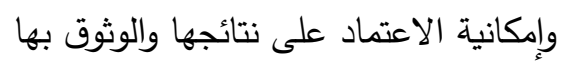

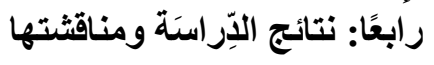


إجابة السُؤال الأول: مـا درجة ممارسـة قادة مدارس التعليم العام بمحافظة ينبع لسلوك

\section{القيادة الأصيلة من وجهة نظر المعلمين؟}

تم حساب المتوسط الحسابي والانحراف المعياري لأبعاد المحور الأول من الاستبانة (درجة

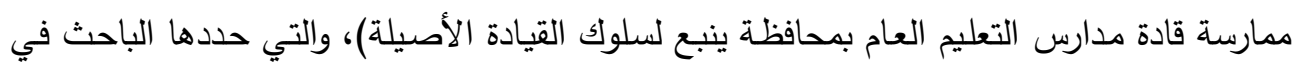
أربعة أبعاد، ومن ثم ترتيب هذه الأبعاد تتازلياً حسب المتوسط الحسابي لكل بعدة لرئ وبيبن ذلك الجدول

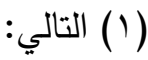

\section{جدول (1)}

المتوسطات الحسابية والانحرافات المعيارية لأبعاد المحور الأول من الاستبانة (درجة ممارسة قادة مدارس التعليم العام بمحافظة ينبع لسلوك القيادة الأصيلة)، مرتبة تنازلياً

\begin{tabular}{|c|c|c|c|c|c|}
\hline الممارسة & ترتيب & الاتحراف المعياري & المتوسط الحسابي & البعد & رقم البعد \\
\hline عالية & 1 & $\cdot, 97 V$ & r,TV & الوعي الذاتي & $\varepsilon$ \\
\hline عالية & r & $\cdot, \wedge r q$ & $r, 01$ & المنظور الأخلاقي الذاتي & r \\
\hline عالية & r & $\cdot, 90 \pi$ & $r, 01$ & شفافية العلاقات & 1 \\
\hline عالية & $\varepsilon$ & $\cdot, 971$ & $r, \Sigma \uparrow$ & المعالجة المتوازنة & r \\
\hline عالية & --- & ת & $r, 0 \leqslant$ & المجموع الكلي للمحور الأول & \\
\hline
\end{tabular}

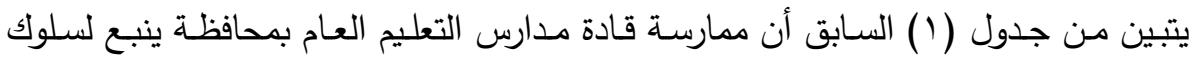
القيادة الأصيلة جاءت بدرجة (عالية) من وجهة نظر المعلين، حيث جاء هندئ المتوسط الحسابي العام

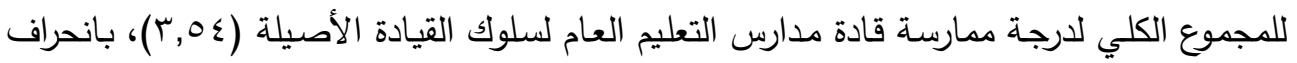
معياري قدره (Trی, ·).

وقد يعزى حصول ممارسة قادة المدارس لسلوك القيادة الأصيلة بدرجة (عالية) من وجهة نظر المعلمين، إلى أن السلوك القيادي لديهم نابع من وازع ديني وقيمي وأخلاقي، وربما يعود كذلك بـادئ إلى الضـوابط والدعايير الرصينة من قبل وزارة التعليم والمبنية على اختبارات مهنية يتم بموجبها

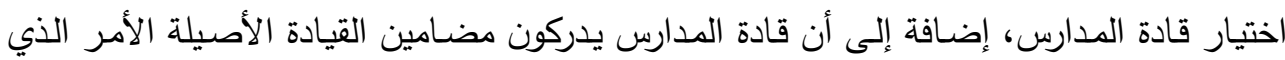
انعكس على تصورات المعلمين حول ممارسة قادة مدارسهم لسلوك القيادة الأصيلة.

ويعزى حصول بعد (الوعي الذاتي) على الترتيب الأول بدرجة عالية إلى الخبرة العريضـة

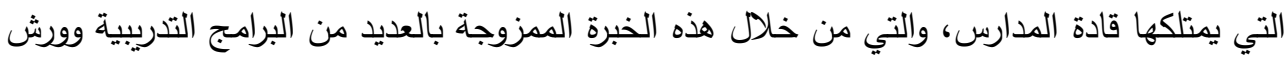


العمل، بالإضافة إلى الدور المحوري لعوامل التتشئة الاجتماعية والثقافية السائدة في مجتمعنا والتي يغلب عليها سمات الصدق والنزاهة والاحترام في التعامل مع المعلمين.

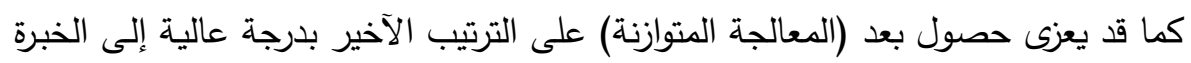

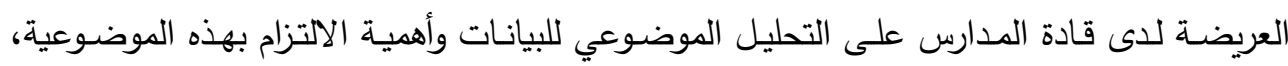
وكذلك أهمية تقبل وجهات نظر المعلمين، كما قد يكون لبرامج التدريب وورش العمل دورًا في هذه لأه النتيجة.

إجابة السُؤال الثانى: ما مستوى العدالة الإجرائية كما يدركها المعلمون في مدارس التعليم

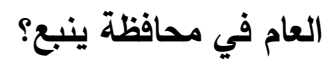

تم حساب المتوسط الحسابي والاتحراف المعياري لاستجابات معلمي مدارس التعليم العام

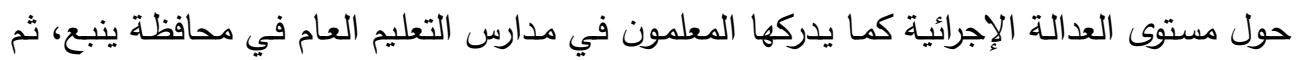
ترتيب تلك الاستجابات تتازلياً بناء على المتوسط الحسابي، كما تبين نتائج جدول (؟) التالي:

\section{جدول رقم (ץ)}

المتوسطات الحسابية والانحرافات المعيارية لاستجابات معلمي مدارس التعليم العام في محافظة ينبع حول مستوى العدالة الإجرائية كما يدركونها، مرتبة تنازلياً.

\begin{tabular}{|c|c|c|c|c|c|}
\hline 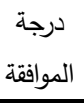 & ت ت ت العبارة & 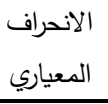 & الحسوسط & 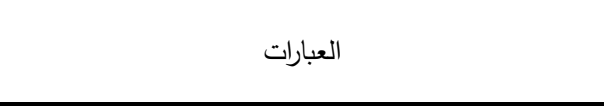 & s \\
\hline عالية & 1 & $1,1 \mathrm{TV}$ & $r, \mathrm{rV}$ & 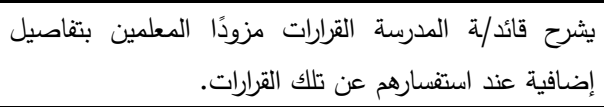 & r \\
\hline عالية & r & $1, r \cdot \lambda$ & $r, 7)$ & يقوم قائد/ة المدرسة بجمع المعلومات الدقيقة والكاملة قبل & r \\
\hline عالية & r & $1, r 19$ & r,o. & يتخذ قائد/ة المدرسة القرارات الوظيفية بشكل غير متحيز & $\varepsilon$ \\
\hline عالية & $\varepsilon$ & o & $r, \Sigma \vee$ & يتم تطبيق جميع القرارات الإدارية على جميع المعلمين بلا & । \\
\hline عالية & $\circ$ & $1, r 01$ & $r, \varepsilon r$ & يحرص قائد/ة المدرسة على أن يبدي كل معلم رأيه قبل & 。 \\
\hline
\end{tabular}




\begin{tabular}{|c|c|c|c|c|}
\hline & & & & اتخاذ القرارات. \\
\hline متوسطة & 1 & 1,YYT & $r, \cdot \varepsilon$ & من قيسح للمعلمين بعدم قبول أو معارضة القرارات التي تتخذ \\
\hline عالية & --- & $1, \cdot 10$ & $r, \varepsilon \vee$ & المجموع الكلي للمحور الثاني \\
\hline
\end{tabular}

يتضح من الجدول رقم (r) السابق؛ أن مستوى العدالة الإجرائية في مدارس التعليم العام

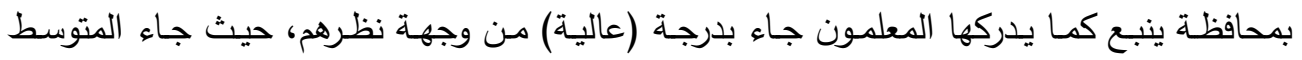

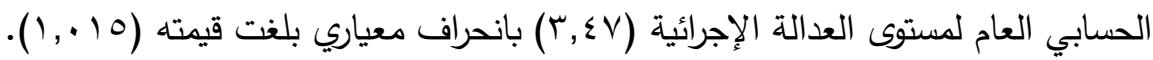

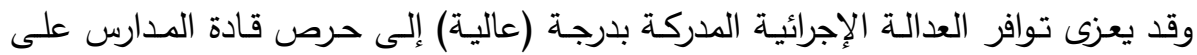

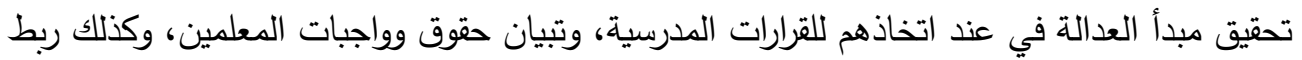
الحوافز بالجهد الذي يقوم بـه المعلم، وأيضًا إدراك قادة المدارس لأهمية العدالة في توزيع المهام

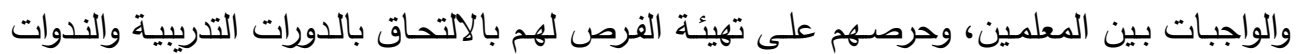
على نحو متساوي.

وقد يرجع حصول الممارسة (يشرح قائد/ة المدرسة القرارات مزودًا المعلمين بتفاصيل إضافية

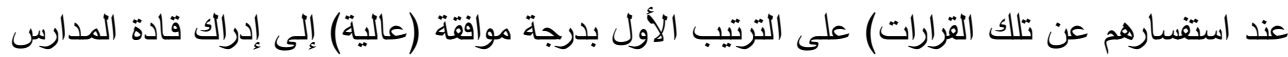

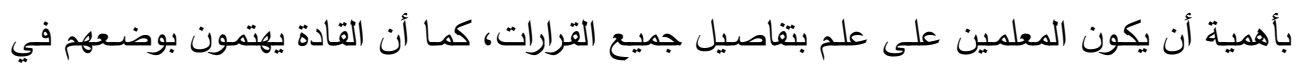
صورة ما يحدث من قرارات ومن أمور داخل المدرسة بوصفهم شركاء حقيقيين في اتخاذ القرارات. إجابة السُؤال الثالث: هل توجد علاقة ارتباطية ذات دلالة إحصائية بين سلوك القيادة الأصيلة

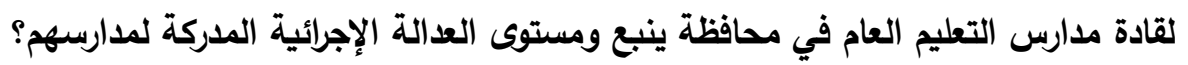

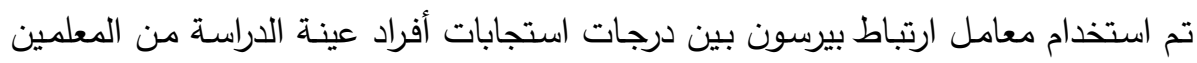
على المحور الأول (درجة ممارسة قادة مدارس التعليم العام بمحافظة ينبع لسلوك القيادة الأصيلة) والمحور الثاني (مستوى العدالة الإجرائية كما يدركها المعلمون)، وجاءت الأدئ النتائج كالتالي: جدول رقم (ب)

نتائج اختبار بيرسون للعلاقة بين درجة ممارسة قادة مدارس التعليم العام بمحافظة ينبع لسلوك

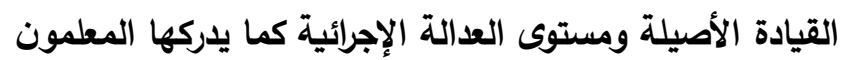

\begin{tabular}{|c|c|c|c|c|}
\hline 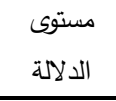 & معامل ارتباط & 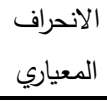 & الحسابي & المتغيرات \\
\hline *ै* & $\cdot, \wedge 0$ & & $r, 0 \leqslant$ & درجة ممارسة قادة مدار التعليم العام بمحافظة ينبع \\
\hline
\end{tabular}




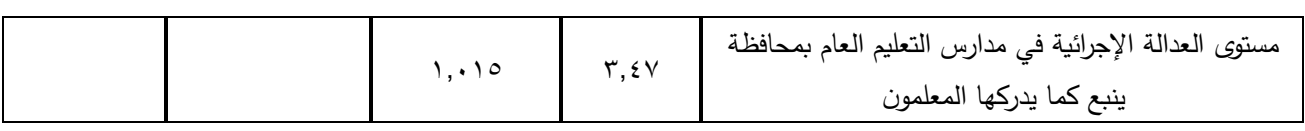

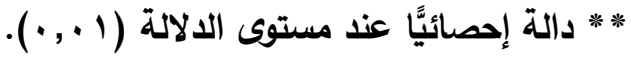

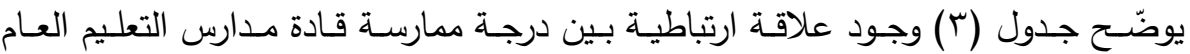

بمحافظة ينبع لسلوك القيادة الأصيلة ومستوى العدالة الإجرائية كما يدركها المعلمون، وذلك بمعامل

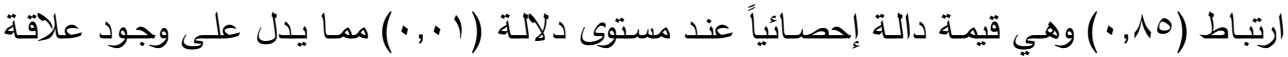
ارتباطية (طردية) عالية القيمة.

ويعزى ذلك إلى الدور الهام لقادة المدارس في إدراك المعلمين لعدالة تطبيق القرارات عليهم

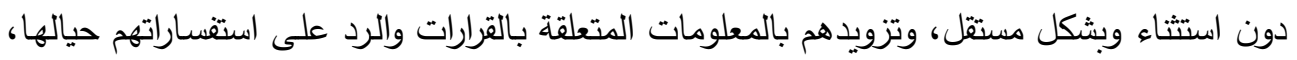
ووعـي قـادة المـدارس بأهميـة سـماع أراء ووجهـات نظـر المعلمـين قبـل اتخـاذهم للقرارات، وتقبـل معارضتهم لها، وذلك عبر تبني هؤلاء القادة لممارسات القائد الأصيل، والتي تتمثل في إدراك القادة لذواتهم ومعرفتهم لنقاط قوتهم وضعفهم، وتوظيف ذلك في ممارساتهم القيادية.

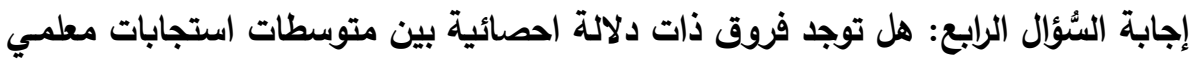

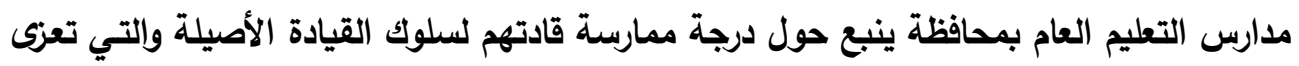

\section{لاختلاف متغيري (الجنس، سنوات الخبرة)؟} أولًا: الفروق باختلاف متغير الجنس:

تم استخدام اختبار (ت) لعينتين مستقلتين للتعرف على دلالـة مـا قد يوجد من فروق بين متوسطات استجابات معلمي مدارس التعليم العام بمحافظة ينبع حول تقديرهم لدرجة ممارسة قادتهم لسلوك القيادة الأصيلة والتي تعزى لاختلاف الجنس، ويوضح نتائجه الجدول (ء) التالي: جدول رقم (؛)

نتائج اختبار (ت) لعينتين مستقلتين للتعرف على دلالة ما قد يوجد من فروق بين متوسطات

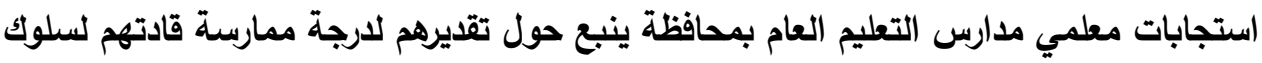

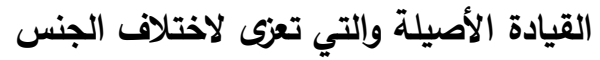

\begin{tabular}{|c|c|c|c|c|c|c|}
\hline مستوى الدلالة & ت & الانحراف المعياري & المتوسط الحسابي & العدد & الجنس & المتغيرات \\
\hline \multirow{2}{*}{$\cdot, \Sigma \vee \cdot$} & \multirow{2}{*}{$\cdot, V Y T$} & $\cdot, q \vee r$ & $r, 00$ & $17 V$ & ذكر & \multirow{2}{*}{ شفافية العلاقات الأول: } \\
\hline & &., $9 \leq$. & $r, \Sigma \wedge$ & $r \leqslant 0$ & أنثى & \\
\hline \multirow[b]{2}{*}{$\cdot, \wedge 9 \Gamma$} & \multirow[b]{2}{*}{$\cdot, 1 T \leq$} & $\cdot, \wedge \cdot 9$ & r,or & $17 \mathrm{~V}$ & ذكر & \multirow{2}{*}{ لمنظور الأخدلاقي الثاني: } \\
\hline & & $\cdot, \wedge 09$ & $r, 01$ & $r \leq 0$ & أنثى & \\
\hline$\cdot, \mu \ldots$ & $1, \cdot \mathrm{r}$ & $\cdot, 9 r \leq$ & r,or & $17 \mathrm{~V}$ & ذكر & البعد الثالث: \\
\hline
\end{tabular}




\begin{tabular}{|c|c|c|c|c|c|c|}
\hline & & $\cdot, 9 \vee \wedge$ & $r, \leqslant Y$ & $r \leqslant 0$ & أنثى & المعالجة المتوازنة \\
\hline \multirow{2}{*}{$\cdot, \varepsilon \mid \vee$} & \multirow{2}{*}{$\cdot, \Lambda \mid r$} & $\cdot, 910$ & $r, v r$ & $17 \mathrm{~V}$ & ذكر & \multirow{2}{*}{ الوعي الذابع: الرابع: } \\
\hline & & $1, \cdots 1$ & $r, T \leq$ & $r \leqslant 0$ & أنثى & \\
\hline \multirow{2}{*}{$\cdot, \varepsilon r \wedge$} & \multirow{2}{*}{$\cdot, \vee \vee \neg$} & $\cdot, 110$ & $r, 01$ & $17 \mathrm{~V}$ & ذكر & \multirow{2}{*}{ المجموع الكلي } \\
\hline & & $\cdot, \wedge \leq 0$ & $r, 01$ & $r \leqslant 0$ & أنثى & \\
\hline
\end{tabular}

يتضح من الجدول رقم (؟) السابق عدم وجود فروق ذات دلالة إحصائية عند مستوى دلالة (0 • . • ) بين متوسطات استجابات معلمي مدارس التعليم العام حول تقديرهم لدرجة ممارسة قادتهم لسلوك القيادة الأصيلة تعزى إلى اختلاف الجنس. ويعزى عدم وجود فروق ذات دلالة إحصائية عند مستوى الدلالة (0., •) بين متوسطات

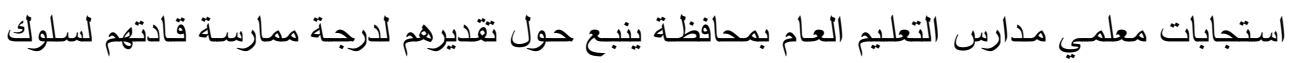

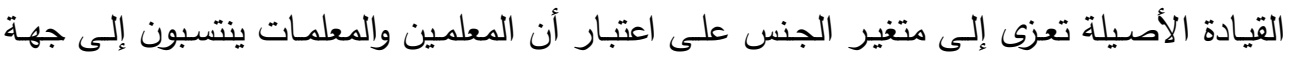

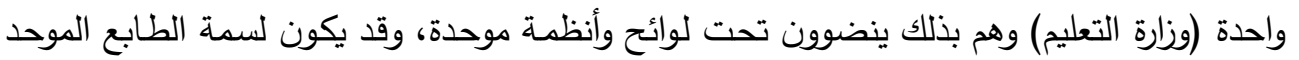
في برامج إعداد وتدريب قادة المدارس دور محوري في تجانس استجابات المعلمين والمعلمات. ثانيًا: الفروق باختلاف متفير سنوات الخبرة:

تم استخدام اختبار تحليل التباين أحادي الاتجاه للتعرف على دلالة ما قد يوجد من فروق بين متوسطات استجابات معلمي مدارس التعليم العام بمحافظة ينبع حول تقديرهم لدرجة ممارسة الداهـ

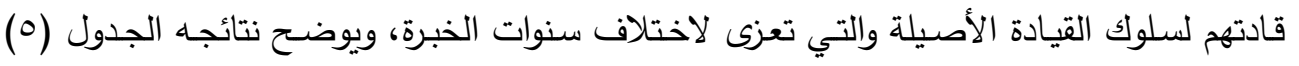

\section{جدول رقم (0)}

نتائج اختبار تحليل التباين أحادي الاتجاه للتعرف على دلالة ما قد يوجد من فروق بين قادتهم لسلوك القيادة الأصيلة والتي تعزى لاختلاف سنوات الخبرة

\begin{tabular}{|c|c|c|c|c|c|c|}
\hline الإحصائية & ف & متوسط المربعات & الحربـة & المربعات & مصادر التباين & المتغيرات \\
\hline \multirow[t]{3}{*}{$\cdot, \leqslant 70$} & $\cdot, \vee \vee \neg \wedge$ & $\cdot, \mathrm{V} \cdot$ & $r$ & $1, \varepsilon$. & بين المجموعات & \multirow{3}{*}{ شفافية العلاقات الأول: } \\
\hline & & $\cdot, 91$ & $\varepsilon .9$ & $r v 1,7$. & المجموعات داخل & \\
\hline & & & हा1 & rVT,.. & الكلى & \\
\hline \multirow[t]{3}{*}{$\cdot, r 99$} & $1, Y_{1}$. & $\cdot, 10$ & $r$ & $1, v \cdot$ & بين المجموعات & \multirow{3}{*}{ المنظور الأخلاقي } \\
\hline & & $\cdot, V \cdot$ & $\varepsilon .9$ & rAv,r. & المجموعات & \\
\hline & & & $\leqslant 11$ & $r \wedge 9, \ldots$ & الكلى & \\
\hline \multirow[t]{2}{*}{$\cdot, 7 \vee \wedge$} & $\cdot, \Gamma \wedge q$ & דוז, • & r & $\cdot, V Y$ & بين المجموعات & \multirow{2}{*}{ المعالجة المتوازنة الثالث: } \\
\hline & & $\cdot ., 94$ & $\varepsilon .9$ & $r \vee \wedge, \vee \leqslant$ & ل داخل & \\
\hline
\end{tabular}




\begin{tabular}{|c|c|c|c|c|c|c|}
\hline & & & & & المجموعات & \\
\hline & & & हा। & 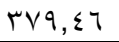 & الكلي & \\
\hline \multirow[t]{3}{*}{$\cdot, r \cdot r$} & 1,199 & $1,1 Y$ & $r$ & $r, Y \leq$ & بين المجموعات & \multirow{3}{*}{ الوعي الذاتي البع: } \\
\hline & & ז & $\varepsilon .9$ & rᄉr,,$\varepsilon$ & المجموعات & \\
\hline & & & «11 & 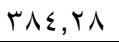 & الكلي & \\
\hline \multirow[t]{3}{*}{$\cdot, \varepsilon \mid V$} & $\cdot, \wedge \vee \neg$ & $\cdot, 71$ & $r$ & $1, Y Y$ & بين المجموعات & \multirow{3}{*}{ المجموع الكلي } \\
\hline & & $\cdot, 79$ & $\varepsilon .9$ & rᄉr, & المجموعات & \\
\hline & & & हा & $r \wedge \varepsilon, \wedge \Lambda$ & الكلي & \\
\hline
\end{tabular}

يتضح من الجدول رقم (0) السابق عدم وجود فروق ذات دلالة إحصائية عند مستوى الدلالة (0 • , •) بين متوسطات استجابات معلمي مدارس التعليم العام بمحافظة ينبع حول تقديرهم لدرجة

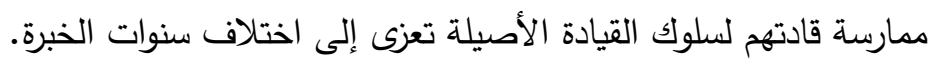
ويعزى عدم وجود فروق ذات دلالة إحصائية عند مستوى الدلالة (0. . • ) بين متوسطات

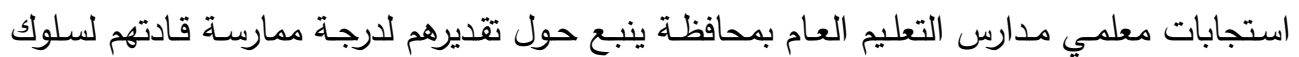

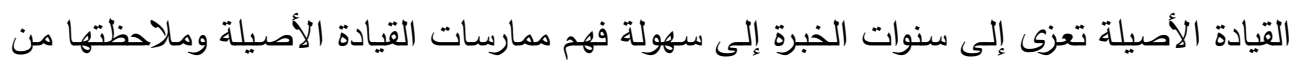
قبل المعلمين والحكم عليها دون أن يكون لمتغير سنوات الخبرة دور محوري في اختلاف استجابات

المعلمين حيالها. توصيات الآّراسنَة:

بناء على ما تم التوصل إليه من نتائج؛ توصي الإِّراسَة بما يلي:

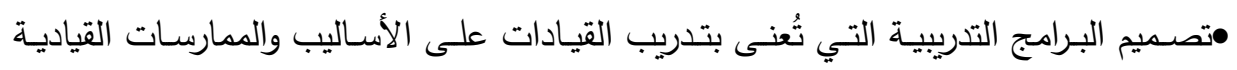
والأخلاقية، لا سيما فيما يتعلق منها بالقيادة الأصيلة، وجعلها من متطلبات الترشح للقيادة

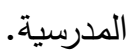

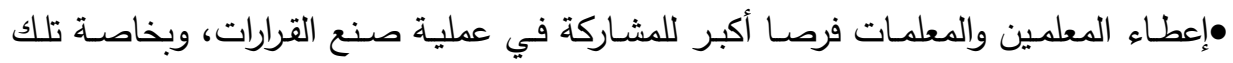
المتعلقة بهم أو التي تؤثر في عملهم من خلال تبني أساليب وممارسات قيادية أصيلة تستتد

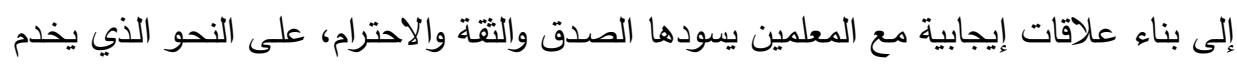
تحقيق الأهداف التعليمية والتتظيمية للمدرسة. •تصميم البرامج التدريبية، وورش العمل، واللقاءات التربوية الموجهة لقادة المدارس، من أجل

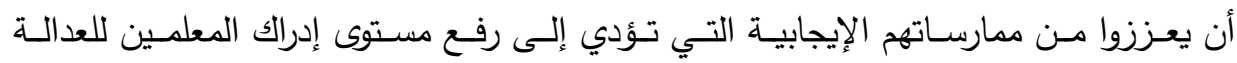
الإجرائية. 
•توجيه قادة الددارس بأهية التحلي بالعدل والإنصاف عند اتخاذ القرارات، وتوزيع المهام ومنح المكافآت للمعلمين لما له من أثر إيجابي على روحهم المعنوية، وانتمائهم للعمل.

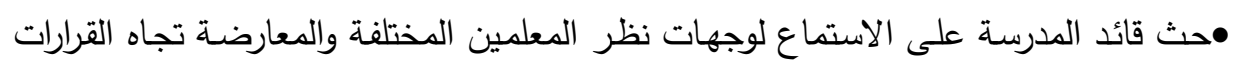
التي يتخذها، واعتبارهم شركاء مهمين يمتلكون المعرفة والخبرة التي قد تفيد قائد المدرسة. مقترحات الآدرّراسَة: تقترح الباحثة إجراء الذّراسَة الآتية مستقبلًا:

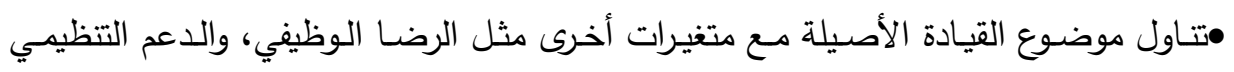
المدرك.

•إجراء دراسات عن القيادة الأصيلة باستخدام مقاييس مختلفة عن هذه الدراسة.

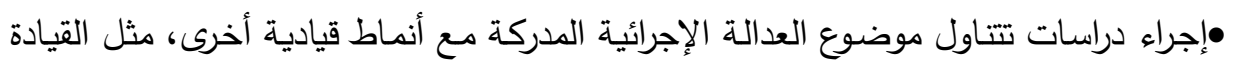
الخادمة، والقيادة التحويلية. •إجراء دراسات تتتاول العدالة الإجرائية المدركة في بيئات تعليمية بمناطق ومحافظات أخرى. •إجراء دراسات تستهدف إعداد " تصور مقترح لرفع مستوى مدركات المعلمين للعدالة الإجرائية

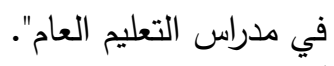
قائمة المراجع المراجع العربيّة:ة

أبو كريم، أحمد فتحي.(10 • ب). العدالة التظيمية لدى مديري المدارس الحكومية بمدينة الرياض

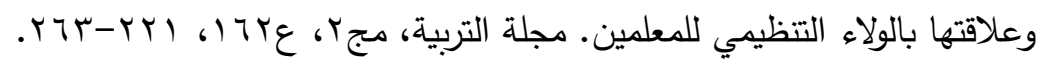

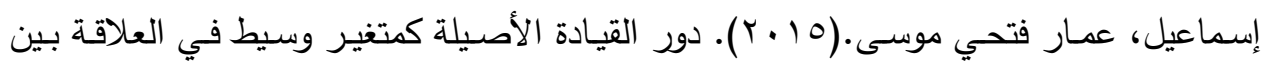

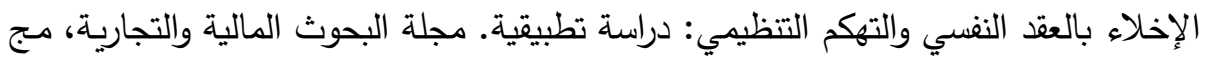

$$
\text { ع ع : - - - 17. }
$$

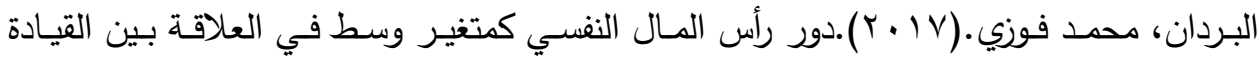

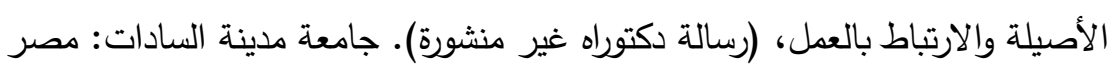

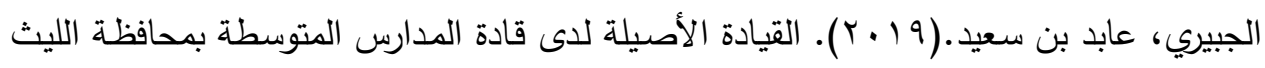

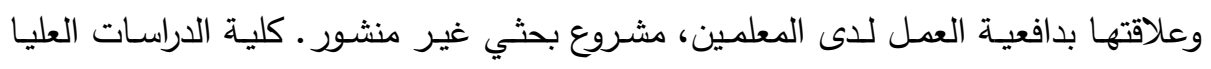

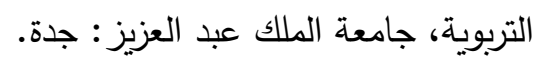




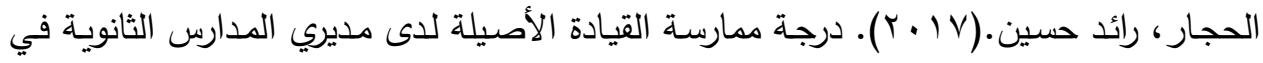

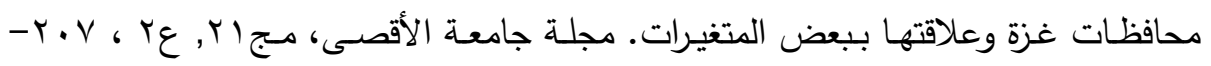

\section{TrE}

الحصنة، علي بن سعيد علي ؛ وعطية، محمد عبدالكريم علي.(9 (19). العدالة التظيمية لدى

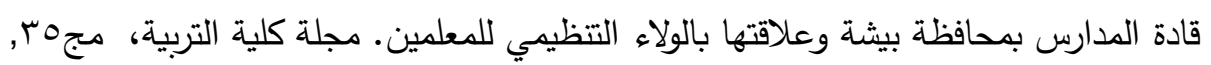

$$
\text { .r }-1 \text { r }
$$

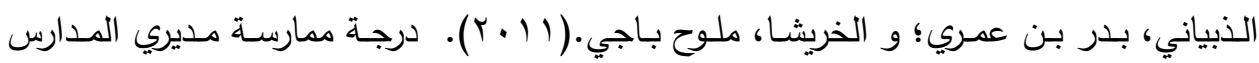

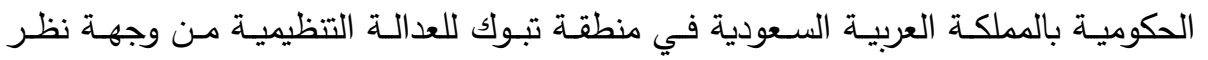
المعلمين, (رسالة ماجستير غير منشورة). جامعة مؤتة: مؤتة.

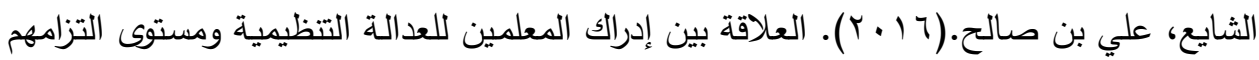

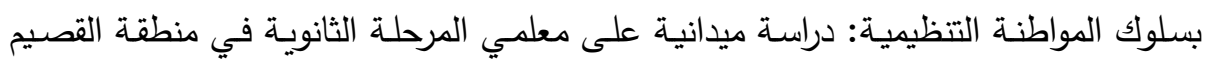

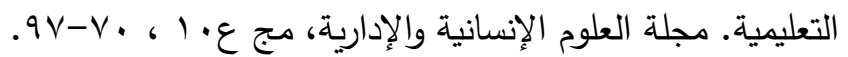

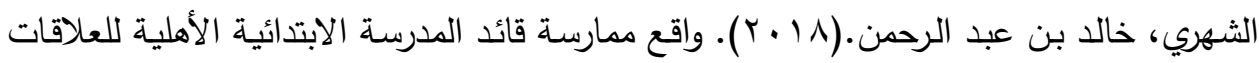

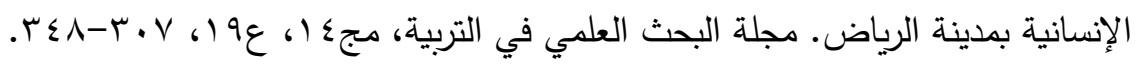

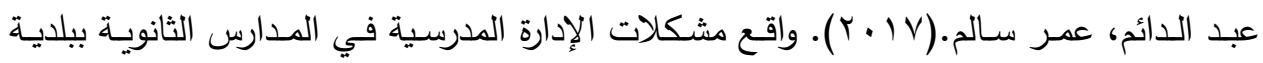

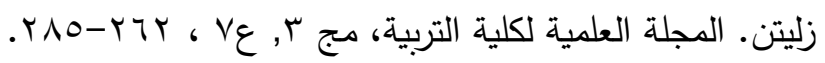

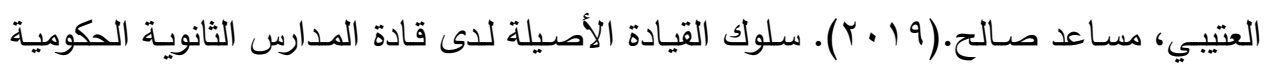
بدحافظة جدة وعلاقتها بالاستغراق الوظيفي لدى المعلمين، مشروع بحثي غير منشور ـ كلية الدراسات العليا التربوية، جامعة الملك عبد العزيز : جدة.

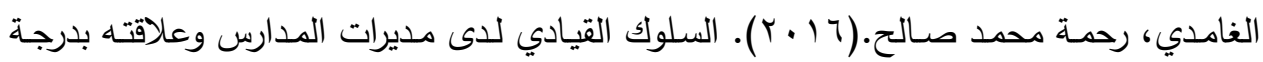

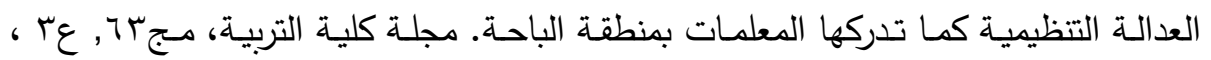

$$
\text { .rAq-rYq }
$$

الفهداوي، فهمي ؛ والقطاونة، نشأت.(؟ . . Y). تأثير العدالة التظيمية في الولاء التظيمي، دراسة

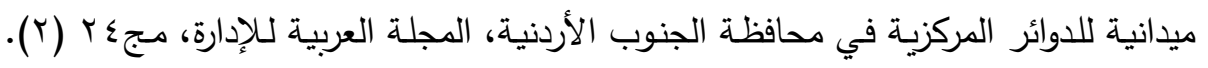
$.0 Y-1$ 


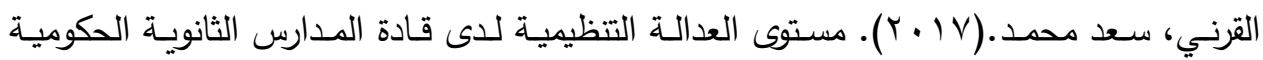

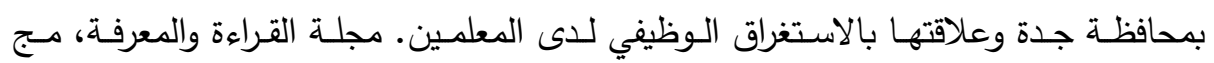

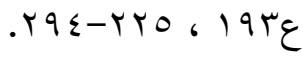

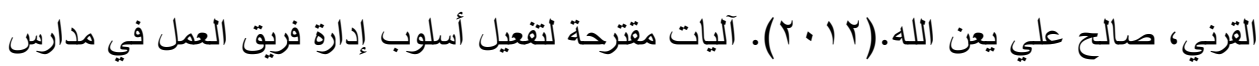
التعليم العام: دراسة تطبيقية على المدارس المتوسطة والثانوية بمحافظة التنفذة. عالم التربية،

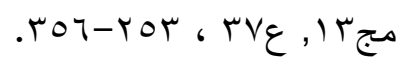

القطاونة، أمل طه ؛ و خليفات، عبدالفتاح صالح.(10 + ب). العدالة التنظيمية وعلاقتها بالنية في

ترك العمل لاى معلمي المدارس الخاصـة في محافظات جنوب الأردن من وجهة نظرهم ، (رسالة ماجستير غير منثورة). جامعة مؤتة: الكرك.

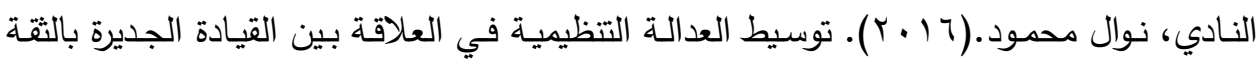

والاستغراق الوظيفي: دراسـة تطبيقية على المستشفيات والمراكز الطبية بجامعة المنصسورة.

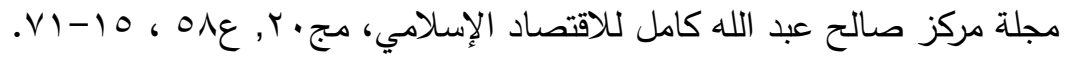

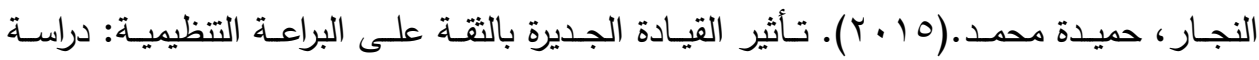

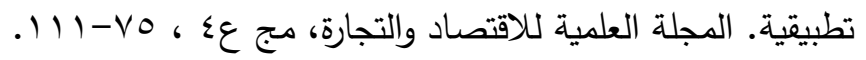

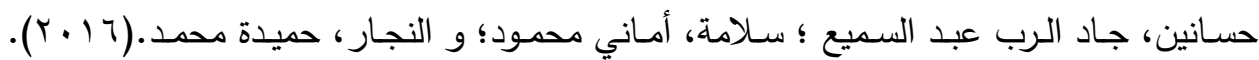
علاقة القيادة الجديرة بالثقـة بتمكين العـاملين بالتطبيق على العاملين بمصلحة الضـرائب المصرية بمنطقة شمال الدلتا. المجلة المصرية للدراسات التجاريـة: جامعة المنصورة - كلية

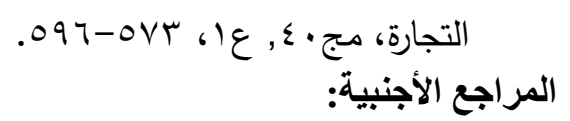

Alinezhad, Mohsen \& Abbasian, Hossein \& Behrangi, Mohammad. (2015). Investigating the Effects of Authentic Leadership of Managers on Organizational Commitment of Teachers with Organizational

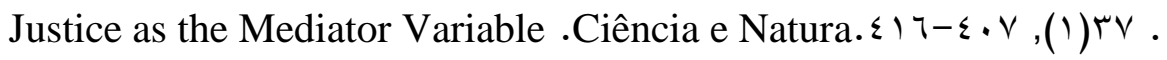

Avolio, B. J., \& Gardner, W. L. (2005). Authentic leadership development: getting to the root of positive forms of leadership. Leadership Quarterly, 16(3), 315-338.

Girgin, Sinan \& Vatansever Bayraktar, Hatice. (2017). Investigation of The Relation Between Trust In The Manager And Organizational Justice. Journal of Education and Practice, 8(8), 208-217. 
Gardner, William \& Avolio, Bruce \& Luthans, Fred \& May, Douglas \& Walumbwa, Fred. (2005). "Can you see the real me?" A self-based model of authentic leader and follower development. The Leadership Quarterly, 16(3), 343-372.

George. B.(2003). Authentic leadership: Rediscovering the secrets to creating lasting value. San Francisco, CA: Jossey-Bass.

Srivastava, A.P. \& Dhar, R.L (2019). Authentic Leadership and Extra Role Behavior: a School Based Integrated Model. Current Psychology ,38: 684-697.

Li, F., YU, K. F., YANG, J., QI, Z., \& FU, J. H-Y. (2014). Authentic leadership, Traditionality, and interactional justice in the Chinese context. Management and Organization Review, 10(2), 249-273.

Feng-I, Feng. (2016). School principals' authentic leadership and teachers' psychological capital: teachers' perspectives. International Education Studies, 9(10), 245-255.

Hussain, Athar ; Haider, Syed Zubair.(2019). Examining the Role of Organizational Justice in Predicting Teachers' Performance in Public and Private Schools. .Journal of Educational Research, 22(1), 46-60.

Ismail, S. N; Abdullah, A.S; Abdullah, A. G. K. (2019). The Effect of School Leaders' Authentic Leadership on Teachers' Job Stress in the Eastern part of Peninsular Malaysia. International Journal of Instruction, 12 (2), 67-80.

Kets de Vries, Manfred, F.R. (2006). The Leader on the Couch: A Clinical Approach to Changing People and Organizations. Cornwall UK: Jossey-Bass.

Walumbwa, F.O., Avolio, B.J., Gardner, W.L., Wernsing, T.S., \& Peterson, S.J. (2008). Authentic Leadership: Development and Validation of a Theory-Based Measure?, Journal of Management, 34 (1), 89-126 